\title{
¿Estrategias de inmunización para un profeta equivocado? La fragilidad argumentativa de la imagen del «Jesús no escatológico» ${ }^{1}$
}

\author{
Fernando BERMEJo RUBio \\ Universidad Complutense de Madrid \\ fjlmbr@yahoo.es
}

\begin{abstract}
RESUMEN
El artículo identifica y examina los argumentos propuestos en las últimas décadas por los defensores de la idea de un «Jesús no escatológico / no apocalíptico», con el objeto de sopesar su valor explicativo. Se concluye que ninguno de ellos resiste el examen crítico, en la medida en que todos están construidos sobre bases endebles. Además, el hecho de que este tipo de argumentos reaparezca una y otra vez en la historia de la investigación sugiere que corresponden a estrategias de inmunización, excogitadas por estudiosos que se sienten incómodos con las implicaciones de un Jesús apocalíptico.
\end{abstract}

Palabras clave: Jesús el galileo, escatología, apocalíptica, argumentos insostenibles, estrategias de inmunización.

\author{
Immunisation Strategies for a Mistaken Prophet? \\ The Fragility of the Image of a «Non-Eschatological Jesus»
}

\begin{abstract}
This article identifies and examines the arguments put forward in the last decades by the proponents of a «non eschatological / non apocalyptic Jesus», in order to assess their explanatory value. It concludes that not one of them withstands critical examination because they are all built on arbitrary grounds and are refuted by extant literary evidence and/or by sound reasoning. Furthermore, the fact that this kind of untenable arguments reappears time and time again in the history of research powerfully suggests that they are the result of an immunisation strategy, contrived by scholars who are embarrassed by the implications of an apocalyptic Jesus.
\end{abstract}

Keywords: Jesus the Galilean, eschatology, apocalypticism, untenable arguments, immunisation strategies.

SUMARIO: 1. Planteamiento de la cuestión. 2. ¿Contenidos sapienciales versus contenidos apocalípticos? 3. ¿Un temprano estrato no apocalíptico en Q? 4. ¿Son las parábolas una prueba de una visión no apocalíptica? 5. ¿Textos extracanónicos como fuentes para un Jesús no apocalíptico? 6. Los dichos sobre el «Hijo del hombre», ¿cruciales e inauténticos? 7. ¿Una «apocaliptización» progresiva de la tradición evangélica? 8. ¿Discontinuidad entre el Bautista, Jesús y la comunidad primi-

\footnotetext{
${ }^{1}$ El presente trabajo ha sido realizado en el marco del proyecto «250 años de investigación sobre el Jesús histórico», FFI-2009-09316.
} 
tiva? 9. ¿Creencia de Jesús en un Reino de Dios ya «presente»? El ejemplo de Lc 17, 20. 10. ¿Éxito del cristianismo como prueba de la ausencia de una escatología fracasada? 11. ¿Fue Jesús malentendido por sus discípulos 12. Conclusiones y reflexiones ulteriores.

FECHA DE RECEPCIÓN: 28 DE 11 DE 2011 FECHA DE ACEPTACIÓN: 07 DE 02 DE 2012

\section{PLANTEAMIENTO DE LA CUESTIÓN}

Entre los escasos elementos que parecerían poder ser considerados virtualmente seguros acerca del predicador galileo Jesús de Nazaret se halla el hecho de que fue una personalidad escatológico-apocalíptica, convencida de la inminente recreación del mundo por la voluntad divina ${ }^{2}$. Tras haber sido establecido este extremo ya desde principios de la investigación moderna por el filólogo deísta Hermann Samuel Reimarus $^{3}$, el exegeta protestante Johannes Weiss lo fundamentó de modo sistemático en una obra clásica, escrita a finales del s. XIX ${ }^{4}$.

La obra de Weiss es un modelo de análisis riguroso, lo que le permitió suscitar la admiración de muchos, aunque las implicaciones de su trabajo suscitaron también la inquietud y las resistencias de muchos más ${ }^{5}$. Diversos estudios posteriores no han hecho sino refrendar las conclusiones de Weiss, en la medida en que el fundamento

\footnotetext{
${ }^{2}$ En la línea de otros estudiosos, recuso el habitual uso que en ciertos ámbitos contrapone nítidamente escatología y apocalíptica. Entiendo por «apocalíptica» una visión del mundo, frecuente en la literatura judía postexílica, en la que es central la idea de que el mundo -aunque creado bueno por Dios- está lleno de maldad en virtud de la actividad de fuerzas diabólicas, y de que Dios va a intervenir pronto con poder para reparar esa situación, juzgar a la humanidad y restablecer la justicia creando una realidad idílica, quizás mediante alguna figura mesiánica. En este sentido, Jesús tuvo una «escatología apocalíptica» (cf. v. gr. B. D. Ehrman, Jesus: Apocalyptic Prophet of the New Millennium, Oxford, 1999; D. C. Allison, Constructing Jesus. Memory, Imagination and History, Grand Rapids, 2010, p. 32). Solo si se restringe el término «apocalíptica» a un tipo de pensamiento (o de literatura) caracterizado por elementos tales como un calendario preciso para el fin, numerología, esoterismo o especulación sobre animales mitológicos puede afirmarse que Jesús no fue «one of the apocalypticists» (J. H. Charlesworth, Jesus Within Judaism: New Light from Exciting Archaeological Discoveries, New York, 1988, 33-42), algo en lo que, a tenor de las fuentes, uno no puede sino estar de acuerdo. Cuando Rudolf Bultmann escribió que «ein Apokalyptiker im eigentlichen Sinn ist Jesus nicht gewesen» (Die Geschichte der synoptischen Tradition, Göttingen, 1931 (1ª ed. 1921), p. 113) sin duda tenía también ese sentido restrictivo en mente. Para una crítica de la antítesis, cf. M. Hengel, «Paulus und die frühchristliche Apokalyptik», en Idem, Paulus und Jakobus. Kleine Schriften III, Tübingen, 2002, pp. 302-417, esp. 318-324.

${ }^{3}$ Según Albert Schweitzer, fue el anónimo de Wolfenbüttel «der erste, der nach achtzehn Jahrhunderten wieder ahnte, was Eschatologie sei», y el que concibió «die Vorstellungswelt Jesu historisch, d.h. als eschatologische Weltanschauung» (Geschichte der Leben-Jesu-Forschung (2a ed. 1913), Tübingen, 19849 , p. 65).

${ }^{4}$ «Etwas anderes ist die nachträgliche religiöse Beurteilung des Wertes einer geschichtlichen Erscheinung, etwas anderes die geschichtliche Erforschung ihrer Lebensanschauungen, ihrer Absichten, ihrer Selbstbeurteilung. Und diese geschichtliche Untersuchung lehrt, dass Jesus für seine Person ebenso wie für sein Werk die entscheidende Wendung erst von der Zukunft erhoffte» (J. Weiss, Die Predigt Jesu vom Reiche Gottes, Göttingen,

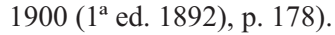

${ }^{5}$ En su prólogo a la edición de 1964 de la obra de Weiss, Rudolf Bultmann escribió estas reveladoras palabras: «Damals ging ein Erschrecken durch die theologische Welt, und ich entsinne mich noch, wie Julius Kaftan im Kolleg über Dogmatik sagte: «Ist das Reich Gottes eine eschatologische Grösse, so ist es ein für die Dogmatik unbrauchbarer Begriff»» (J. Weiss, Die Predigt Jesu, «Geleitwort», p. V).
} 
textual del paradigma apocalíptico es abrumador ${ }^{6} \mathrm{y}$ en que su capacidad explicativa es amplísima ${ }^{7}$. De hecho, hace medio siglo Rudolf Bultmann podía dar a entender que esta idea tenía el carácter de un consenso ${ }^{8}$.

No obstante, en la literatura de los últimos veinticinco años se ha producido un cuestionamiento de tal consenso. Varios autores -en especial, norteamericanos- han desafiado la imagen establecida ${ }^{9}$ y defienden ahora la hipótesis de un «Jesús no escatológico» ${ }^{10}$, que no concibió el Reino de Dios como un acontecimiento futuro, sino una realidad que ha de ser experimentada solo en el presente ${ }^{11}$. Estos autores hablan de «colapso de la hipótesis apocalíptica» ${ }^{12}$, y pretenden incluso que la suya es una opinión generalizada ${ }^{13}$.

¿Qué puede decirse de esta pretensión? Por una parte, una visión que pone en jaque la idea heredada resulta estimulante y puede concitar fácilmente la simpatía no solo de quienes son proclives a épater le bourgeois, sino también la de quienes poseen un genuino sentido crítico ${ }^{14}$. En efecto, en la investigación sobre Jesús y los orí-

${ }^{6}$ El material está útilmente expuesto en D. C. Allison, Constructing Jesus, pp. 33-43 (y comentado en 4386); Idem, «A Plea for Thoroughgoing Eschatology», Journal of Biblical Literature 113 (1994), pp. 651-668. Incluso Crossan, que postula un Jesús no apocalíptico, reconoce que «Jesus makes apocalyptic statements at almost every level and in every genre of the tradition» (R. J. Miller (ed.), The Apocalyptic Jesus: A Debate, Santa Rosa, 2001, p. 122).

${ }^{7}$ Cf. v. gr. Allison, Constructing Jesus, pp. 135-137; Ch. Rowland, Christian Origins. An Account of the Setting and Character of the most Important Messianic Sect of Judaism, London, 1985, pp. 148ss.

8 «Nobody doubts that Jesus' conception of the Kingdom of God is an eschatological one - at least in European theology and, as far as I can see, also among American New Testament scholars» (R. Bultmann, Jesus Christ and Mythology, New York, 1958, p. 13).

${ }^{9}$ El lenguaje del desafío («challenge») es usado v. gr. por M. J. Borg, «A Temperate Case for a NonEschatological Jesus», en Idem, Jesus in Contemporary Scholarship, Valley Forge, 1994, pp. 47-68, esp. 47 (publicado originalmente en Foundations and Facets Forum 2 (1986), pp. 81-102).

${ }^{10}$ Cf. Borg, «A Temperate Case»; Idem, «Con: Jesus Was Not an Apocalyptic Prophet», en Miller (ed.), The Apocalyptic Jesus, pp. 31-48; J. D. Crossan, The Historical Jesus: The Life of a Mediterranean Jewish Peasant, San Francisco, 1991; Idem, «Con: Jesus Was Not an Apocalyptic Prophet», en Miller (ed.), The Apocalyptic Jesus, pp. 49-68; S. J. Patterson, «The End of Apocalypse: Rethinking the Historical Jesus», Theology Today 52 (1995), pp. 29-48 («the latest phase of research into the history of the gospel tradition has produced too many results that do not fit the apocalyptic paradigm»); Idem, The God of Jesus: The Historical Jesus and the Search for Meaning, Harrisburg, 1998, p. 171. Cf. D. S. Du Toit, «Redefining Jesus: Current Trends in Jesus Research», en M. Labahn / A. Schmidt (eds.), Jesus, Mark and Q. The Teaching of Jesus and its Earliest Records, Sheffield, 2001, pp. 82-124, esp. 110-113.

${ }^{11}$ Esta posición debe ser distinguida de la de los autores (como J. P. Meier y otros) que, aun aceptando la imagen del «Jesús escatológico», otorgan una gran importancia a la idea del «reino presente». Esta posición, no obstante, es también discutible; cf. v. gr. A. Piñero, «Notas críticas a la presentación usual hoy del Reino de Dios según Jesús de Nazaret», Ilu, 17 (2012), 119-147.

${ }^{12}$ Borg, «A Temperate Case», p. 59; Patterson, «The End of Apocalypse», p. 34.

13 «A new consensus» (H. Koester, «Jesus the Victim», Journal of Biblical Literature 111 (1992), pp. 315,6, n. 12); «The majority of scholars no longer thinks that Jesus expected the end of the world in his generation» (Borg, Jesus, A New Vision: Spirit, Culture, and the Life of Discipleship, San Francisco, 1987, p. 14). Cabe preguntarse por qué vías ha llegado Borg a esta conclusión. De hecho, en una obra más reciente afirma que, respecto a este tema, su «impression is that the discipline today is about evenly divided» (Jesus: Uncovering the Life, Teachings, and Relevance of a Religious Revolutionary, San Francisco, 2006, p. 252).

${ }^{14}$ Especialmente cuando la idea heredada es calificada de «ortodoxia»; cf. M. J. Borg, «An Orthodoxy Reconsidered: the End-of-the-World Jesus», en L. D. Hurst - N. T. Wright (eds.), The Glory of Christ in the 
genes del cristianismo abundan las distorsiones motivadas por presupuestos ideológicos e intereses de todo tipo ${ }^{15}$, por lo que no es en absoluto descabellado pensar que el cuestionamiento de cualquier idea bien asentada está justificado.

Por otra parte, ciertamente, alguien que conozca la historia de la investigación podría albergar dudas razonables acerca de la legitimidad de las mencionadas pretensiones, dado que el fracaso de las expectativas escatológicas de Jesús ha suscitado numerosos intentos de absolver al predicador galileo de tales expectativas o de reinterpretarlas en un sentido espiritualizante o moralizante; de hecho, buena parte de la exégesis y la teología neotestamentaria de los últimos dos siglos ha sido caracterizada como «el esfuerzo por liberar a Jesús de la apocalíptica» ${ }^{16}$. No obstante, dado que no puede descartarse a priori que un nuevo enfoque logre lo que anteriormente no se había conseguido, y que una posición disidente con la visión mayoritaria pueda estar en lo cierto, el objetivo del presente artículo es llevar a cabo una revisión sistemática de sus fundamentos. En lo que sigue, procederé a identificar y a exponer los argumentos esgrimidos por los defensores del «Jesús no apocalíptico», así como a someterlos a una crítica minuciosa, con el objeto de evaluar su poder de convicción. Los resultados, como veremos, son muy instructivos no solo en lo que respecta a la naturaleza histórico-religiosa de Jesús el galileo, sino en lo concerniente al carácter de la propia historia de la investigación.

\section{2. ¿CONTENIDOS SAPIENCIALES VERSUS CONTENIDOS APOCALÍPTICOS?}

En los Evangelios canónicos hay una apreciable cantidad de material sapiencial y enseñanza ética, lo que permite ver a Jesús como un maestro. Apelando a un criterio de consistencia, varios estudiosos han afirmado que la existencia de estos elementos contradice el material apocalíptico, y que por tanto no pueden provenir de la misma fuente. Una enseñanza sapiencial y ética presupone la creencia en la continuación de las condiciones actuales del mundo, por lo cual -se argumenta- es muy improbable que Jesús se haya dedicado a la predicación de un fin inminente ${ }^{17}$.

New Testament: Studies in Memory of George Bradford Caird, Oxford, 1987, pp. 207-217; Idem, «A Temperate Case», p. 49.

${ }^{15}$ En varios artículos he mostrado la presencia determinante de esos presupuestos, incluso en el modelo historiográfico predominante sobre la historia de la investigación; cf. F. Bermejo, «The Fiction of the «Three Quests>. An Argument for Dismantling a Dubious Historiographical Paradigm», Journal for the Study of the Historical Jesus 7 (2009), pp. 211-253, esp. 243-250.

16 «Das angestrengte Bemühen, Jesus vor der Apokalyptik zu retten» (K. Koch, Ratlos vor der Apokalyptik. Eine Streitschrift über ein vernachlässigtes Gebiet der Bibelwissenschaft und die schädlichen Auswirkungen auf Theologie und Philosophie, Gütersloh, 1970, p. 55; Idem, «Jesus apokalyptisch», Zeitschrift für Neues Testament 3 (1999), pp. 41-49). Sobre este aspecto, resulta muy instructivo J. Frey, «Die Apokalyptik als Herausforderung der neutestamentlichen Wissenschaft. Zum Problem: Jesus und die Apokalyptik», en M. Becker - M. Öhler (eds.), Apokalyptik als Herausforderung neutestamentlichen Theologie, Tübingen, 2006, pp. 23-94.

${ }^{17}$ Cf. v. gr. M. J. Borg, «Jesus and Eschatology: Current Reflections», en Idem, Jesus and Contemporary Scholarship, Harrisburg, 1994, pp. 69-96, 82-83; Idem, «Jesus Was Not an Apocalyptic Prophet», en Miller 
Solo en apariencia, sin embargo, posee este argumento capacidad de convicción. Ante todo, incluso si se admitiera la incompatibilidad de ambas tradiciones, esta propuesta presupondría la existencia de una extrema coherencia en Jesús: como -se dicelo sapiencial y lo escatológico no se pueden conciliar, Jesús no los ha conciliado. Ahora bien, dado lo que sabemos de la naturaleza humana en general, y de la de los individuos religiosos y carismáticos en particular -en la que la lógica rigurosa brilla a menudo por su ausencia-, esta conclusión no está justificada ${ }^{18}$. Por lo demás, no hay motivo alguno para suponer que lo que los evangelistas -que obviamente incluyeron material de distinto signo en sus escritos- consideraron compatible no habría podido ser juzgado así por el propio Jesús.

En realidad, no parece existir incompatibilidad entre ambos aspectos. Por ejemplo, en algunos textos de Qumrán -en particular, $1 Q / 4 Q$ Instrucción y $1 Q / 4 Q$ Misterios-que muestran un interesante desarrollo de la tradición sapiencial palestina (sensiblemente diferente al tipo de reflexión sapiencial que se halla en textos como Qohelet, Job, Proverbios o Sirácida), la reflexión sapiencial se une con motivos apocalípticos tales como una partición dualista de la humanidad o un juicio escatológi$\operatorname{co}^{19}$. De aquí se sigue que la habitual decisión de someter varios logia de la tradición jesuánica a la alternativa «sapiencial o apocalíptico» es metodológicamente infundada, pues estos dos ámbitos se entreveran ya antes del cambio de $\mathrm{era}^{20}$. Dicho de otro modo, presuponer que toda tradición sapiencial es ipso facto enteramente no apocalíptica (o viceversa) es erróneo, e implica el desconocimiento de la variedad de posibilidades que ofrece la literatura disponible. La combinación de parénesis moral y convicción escatológica es visible no solo en la comunidad de Qumrán -que mantuvo al mismo tiempo la creencia en una inminente redención del mundo y una estric-

(ed.), The Apocalyptic Jesus, p. 36. Esta pretensión tiene una larga historia: cf. v. gr. F. Greenwood Peabody, The Christian Life in the Modern World, New York, 1914, 24-25; J. H. Leckie, The World to Come and Final Destiny, Edinburg, 1918, p. 55 (sobre Jesús): «When taken by themselves they certainly suggest the idea that His mind was dominated and possessed- by the conviction that the end of all things was at hand. Yet there are features of His doctrine which imply that He did not feel this sense of approaching climax. The sweep and reach of His ethical demands, which call men to be perfect as the Father in heaven is perfect, seem to require a long period of time for their fulfillment» (p. 55).

18 «The ability to hold together prophetic urgency with patience and indeed postponement is deeply intrinsic to the biblical and Jewish apocalyptic milieux» (M. Bockmuehl, «Resistance and Redemption in the Jesus Tradition», en M. Bockmuehl - J. Carleton Paget, Redemption and Resistance: The Messianic Hopes of Jews and Christians in Antiquity, London, 2007, pp. 65-77, p. 75, cursivas originales). Sobre la falta de coherencia en individuos carismáticos -y sobre las ventajas que ello supone para el impacto que produce en sus oyentes-, cf. J. T. Sanders, «The Criterion of Coherence and the Randomness of Charisma: Poring through Some Aporias in the Jesus Tradition», New Testament Studies 44 (1998), pp. 1-25.

${ }^{19}$ Cf. A. Lange, «Die Weisheitstexte von Qumran: Eine Einleitung», en C. Hempel, A. Lange, H. Lichtenberger (eds.), The Wisdom Texts from Qumran and the Development of Sapiential Thought, Leuven, 2002, pp. 3-30; F. García Martínez, «Wisdom at Qumran: Worldly or Heavenly?», en Idem (ed.), Wisdom and Apocalypticism in the Dead Sea Scrolls and in the Biblical Tradition, Leuven, 2003, pp. 1-15 («4QInstruction could represent a new development with its fusion of traditional biblical wisdom with apocalyptic elements»: ibidem, p. 6).

${ }^{20}$ Cf. J. J. Collins, «Wisdom, Apocalypticism and Generic Compatibility», en Idem, Seers, Sibyls and Sages in Hellenistic Judaism, Leiden, 1997, pp. 385-404. 
ta observancia de los preceptos de la Torá, sin hallar contradicción en ello ${ }^{21}-$, sino en otros textos judíos y cristianos (v. gr. 2 Baruc, Testamentos de los Doce Patriarcas, cartas de Pablo, Santiago, 1 Pedro). Resulta francamente peregrino, por tanto, pretender que no puede combinarse lo que, una y otra vez, las fuentes combinan, y del modo más natural.

Un ejemplo mucho más cercano aún, temporal, espacial e ideológicamente a Jesús, lo tenemos en Juan el Bautista, un claro exponente de predicador apocalíptico. Aunque los Evangelios canónicos minimizan el aspecto sapiencial y ético de la enseñanza del Bautista, resulta innegable que este fue también un maestro. Por una parte, Lc 3, 10-14 conserva algo de su enseñanza ${ }^{22}$; Juan es invocado como maestro en Lc 3, 12 ( $\delta 1 \delta \alpha ́ \sigma \kappa \alpha \lambda \varepsilon)$ y como rabbí en Jn 3, 26; y sus discípulos ( $\mu \alpha \theta \eta \tau \alpha i ́)$ son mencionados a menudo en todos los Evangelios ${ }^{23}$. Además, incluso en la breve noticia de Flavio Josefo sobre el Bautista contenida en Antiquitates Judaicae hallamos varias referencias a su enseñanza, que -a tenor de lo que dice el historiador judío sobre su capacidad de enardecer a quienes le escuchaban- debió de ser singularmente elocuente ${ }^{24}$.

De hecho, en el caso de Jesús, la sabiduría «subversiva» y la ética de tipo radical que se le atribuye -que anima a despojarse de las posesiones y a una vida de seguimiento- resulta más comprensible precisamente en un contexto de entusiasmo escatológico: la convicción en la proximidad del fin del orden presente del mundo permite dar el paso de relativizar más fácilmente las conductas «normales» y radicalizar las exigencias morales ya contenidas en el acervo tradicional de las Escrituras judías. La decisión a favor de tal praxis adquiere igualmente más sentido en el contexto de la expectación de una transformación universal inminente.

En suma, el intento de negar el carácter apocalíptico de la predicación de Jesús en virtud de su presunta incompatibilidad con el material sapiencial y ético no se sostiene, pues -como evidencian las fuentes y refrenda la reflexión- no existe necesariamente una antítesis entre lo apocalíptico y lo sapiencial. Ciertamente, la coexistencia de ambas magnitudes puede resultar paradójica al sentido común, pero el considerable trecho entre la paradoja y la contradicción nunca debería ser soslayado por una reflexión que aspire al rigor científico.

${ }^{21}$ Cf. A. I. Baumgarten, The Flourishing of Jewish Sects in the Maccabean Era: An Interpretation, Leiden, 1997, pp. 176-177; J. Trebolle, «Los esenios de Qumrán, entre el dominio de la Ley y la huida apocalíptica», en F. García Martínez - J. Trebolle, Los hombres de Qumrán. Literatura, estructura social y concepciones religiosas, Madrid, 1993, pp. 63-89.

22 Sobre este aspecto, cf. J. Taylor, John the Baptist within Second Temple Judaism. A Historical Study, London, 1997, pp. 101-154; P. Hollenbach, «Social Aspects of John the Baptizer's Preaching Mission in the Context of Palestinian Judaism», Aufstieg und Niedergang der Römischen Welt II.19.1, pp. 850-875, esp. 860 ss.

${ }^{23}$ Mc 2, 18; 6, 28-29; Mt 9, 14; 11, 2; 14, 12; Lc 5, 33; 7, 18ss; Jn 1, 22.32.35.37; 3, 25.27.

24 «Exhortaba a los judíos a practicar la virtud» (Ant 18, 117); «Se enardecían oyendo sus palabras» (Ant $18,118)$. 


\section{3. ¿UN TEMPRANO ESTRATO NO APOCALÍPTICO EN LA FUENTE DE LOS LOGIA (Q)?}

El argumento expuesto en la sección anterior tiene una variante desarrollada a partir de la investigación sobre Q, la designación que recibe la fuente (en alemán, Quelle) postulada para explicar la composición de los Evangelios de Mateo y Lucas. El trabajo sobre esta fuente ha llevado a algunos autores a distinguir al menos dos (a veces, tres) estratos, el más temprano de los cuales (designado a menudo como $\mathrm{Q}^{1}$ ) tendría un carácter sapiencial. Lo que aquí nos interesa es el hecho de que otros estudiosos - como Burton Mack o Stephen Patterson-han utilizado esta distinción de estratos para extraer conclusiones acerca de la figura histórica de Jesús. De este modo, han argüido que el contenido escatológico entró en esta fuente en una fase secundaria de elaboración, el llamado estrato $\mathrm{Q}^{2}$. De aquí se concluye que la escatología apocalíptica no sería atribuible a Jesús, sino a sus seguidores ${ }^{25}$.

Existen, sin embargo, una gran cantidad de objeciones a este procedimiento. La primera es que, aunque a menudo se habla de $\mathrm{Q}$ como de un objeto bien conocido, y aunque su existencia es presupuesta por muchos, lo cierto es que no deja de ser una hipótesis, para la que hay hipótesis alternativas ${ }^{26}$. Además, aun si se acepta su existencia conjetural, no solo ignoramos sus contenidos exactos ${ }^{27}$, sino que la teoría de Kloppenborg sobre la existencia de tres estadios sucesivos en Q presenta problemas, como muestra la existencia de varias alternativas razonables ${ }^{28}$.

Pero incluso si este modelo estratigráfico de Q fuera válido, no se sigue de ello nada seguro sobre la figura histórica de Jesús ${ }^{29}$ : habida cuenta de que la elaboración de Q habrá tenido lugar en unos pocos años o -a lo sumo- unas pocas décadas, el estrato más antiguo no tiene por qué ser necesariamente el más originario históricamente hablando; en estas circunstancias, la prioridad cronológica no es determinante ${ }^{30}$. El

\footnotetext{
25 «Aphoristic wisdom is characteristic for the earlier layer. This turns the table on older views of Jesus as an apocalyptic preacher and brings the message of Jesus around to another style of speech altogether» (B. Mack, A Myth of Innocence: Mark and Christian Origins, Philadelphia, 1988, p. 59). Citando también a Crossan, este autor prosigue: «To notice the aphoristic quality of the sayings of Jesus and isolate an early «sapiential» layer in their collection is to define a particular style of speech of great significance for the quest of the historical Jesus» (ibidem, p. 60); cf. Idem, The Lost Gospel: The Book of Q and Christian Origins, San Francisco, 1993, pp. 105-147.

${ }^{26}$ Cf. v. gr. M. Goodacre, The Case against Q, Harrisburg, 2002; M. Goodacre - N. Perrin (eds.), Questioning Q. A Multidimensional Critique, Downers Grove, 2004.

${ }^{27}$ Obsérvese que ni Mateo ni Lucas reprodujeron todo el contenido de Marcos, y por tanto no hay razones para suponer tampoco que reprodujeron la totalidad de la fuente de los logia.

${ }^{28}$ Cf. Allison, Constructing Jesus, pp. 118-125, que contiene abundante bibliografía crítica con la obra de Kloppenborg y los análisis estratigráficos de Q (esp. pp. 119-120, n. 405).

${ }^{29}$ De hecho, Kloppenborg ha expresado reservas a la hora de usar $\mathrm{Q}^{1}$ como fuente para el estudio de Jesús; cf. «The Sayings Gospel Q and the Question of the Historical Jesus», Harvard Theological Review 89 (1996), pp. 307-344.

${ }^{30}$ Ténganse en cuenta también las siguientes observaciones de Ben Meyer: «Since the most authoritative witnesses to the career of Jesus did not immediately disappear from the stage of history and the ongoing life of the church, later traditions could have arisen, and no doubt did arise, to correct or clarify earlier traditions in historically valid fashion. We cannot then exclude the possibility that a later tradition might be historically
} 
propio Kloppenborg ha admitido la posibilidad de que material de la segunda fase sea muy antiguo y aun se remonte a Jesús ${ }^{31}$. Además, no podemos tener la certeza de que cada estrato contiene todo lo que cada uno de sus «autores» tenía a su disposición, pues sin duda todos ellos fueron el fruto de una selección de material. Utilizar un texto relativamente breve como clave para reescribir la historia de los orígenes cristianos es algo francamente muy arriesgado ${ }^{32}$.

Una determinante objeción adicional es que otro de los presupuestos cruciales en los que se basa el intento de utilizar $\mathrm{Q}^{1}$-la existencia de una diferencia apreciable en las concepciones escatológicas de $\mathrm{Q}^{1} \mathrm{y} \mathrm{Q}^{2}$ - presenta todos los visos de ser erróneo. En efecto, hay toda una serie de perícopas en ese primer estrato hipotético que implican intensas convicciones escatológicas, como las Bienaventuranzas (Q 6, 20b-23) -a pesar de su indudable componente moral, constituyen promesas utópicas de un estado futuro en que Dios librará al mundo de la pobreza, la injusticia, el hambre y el dolor-, las referencias al juicio en Q 6, 37-38, los dichos sobre la venida del Reino de Dios en Q 10, 9 y Q 11, 2, o la referencia a la gehenna (que presupone la resurrección y el castigo de los malvados) en Q 12,5 , etc ${ }^{33}$. Hasta tal punto es así, que el propio Kloppenborg ha señalado la ausencia de una discontinuidad fundamental entre los dos estratos ${ }^{34}$.

La hipotética fuente $\mathrm{Q}^{1}$ no está libre de escatología ni de apocalíptica ${ }^{35}$, pero aun si lo estuviera, todavía habría una objeción ulterior que habría que sortear: ¿en virtud de qué criterios se debería privilegiar $\mathrm{Q}^{1}$ sobre varias fuentes antiguas -como la hi-

better than a more primitive tradition. Finally, there is nothing to prevent the most primitive form of a tradition from appearing in a late, even the latest, redaction» (B. F. Meyer, «Objectivity and Subjectivity in Historical Criticism of the Gospels», en D. L. Dungan (ed.), The Interrelations of the Gospels. A Symposium led by M.-É Boismard - W. R. Farmer - F. Neyrinck, Jerusalem 1984, Louvain, 1990, pp. 546-565, esp. 551-552).

${ }^{31}$ «To say that the wisdom components were formative for Q and that the prophetic judgment oracles and apothegms describing Jesus' conflict with 'this generation' are secondary is not to imply anything about the ultimate tradition-historical provenance of any of the sayings. It is indeed possible, indeed probable, that some of the materials from the secondary compositional phase are dominical or at least very old, and that some of the formative elements are, from the standpoint of authenticity or tradition-history, relatively young. Traditionhistory is not convertible with literary history» (J. S. Kloppenborg, The Formation of Q. Trajectories in Ancient Wisdom Collections, Harrisburg, $1999^{2}$, pp. 244-245, cursivas originales). Véanse también al respecto las consideraciones de J. Schröter, «The Historical Jesus and the Sayings Tradition: Comments on Current Research», Neotestamentica 30 (1996), 151-168.

32 Téngase en cuenta que un número apreciable de datos históricos básicos sobre Jesús -desde su asociación con Juan el Bautista hasta su crucifixión por Poncio Pilato- no aparecen en el denominado $Q^{1}$.

${ }^{33}$ Cf. Collins, «Wisdom, Apocalypticism and Generic Compatibility», pp. 401-403.

34 «One must presume a basic continuity in eschatological outlook between $\mathrm{Q}^{1}$ and $\mathrm{Q}^{2}$ in spite of the changes in idiom» («Sayings Gospel Q», p. 337), cf. Idem, Excavating Q, Edinburgh, 2000, p. 151.

${ }^{35}$ Cf. C. M. Tuckett, «Eschatology in Q», en Idem, $Q$ and the History of Early Christianity: Studies on $Q$, London, 2004, pp. 139-163 («It is undeniable that Q does contain some elements usually called (apocalyptic) [...] large parts of $Q$ are dominated by ideas of a futurist eschatology»: ibidem, 162-163). También Koester ha concluido que «the image of Jesus that is accessible through the most original version of Q is that of an eschatological prophet» (H. Koester, «The Sayings of Jesus and Their Image of Jesus», en W. L. Petersen, J. S. Vos \& H. J. de Jonge (eds), Sayings of Jesus: Canonical and Non-Canonical: Essays in Honour of Tjitze Baarda, Leiden, 1997, pp. 137-154). 
potética $\mathrm{Q}^{2}$, Pablo (que atribuye la expectativa presente en 1 Tes 4,15-17 a «la palabra del Señor») y Marcos- que contienen abundante material que presenta a Jesús como un predicador apocalíptico? Por lo demás, ¿de dónde provendría ese material, si Jesús no hubiera sido quien Johannes Weiss argumentó que fue?

Cuando se consideran todas estas objeciones, la debilidad metodológica de la pretensión de convertir un constructo consistente en acumular hipótesis (muy discutibles o improbables) sobre hipótesis (muy discutibles) en un acceso fiable a la figura histórica de Jesús se hace patente ${ }^{36}$. La distinción de estratos en $\mathrm{Q}$ no permite cuestionar con fundamento la imagen escatológico-apocalíptica de Jesús.

\section{4. ¿SON LAS PARÁBOLAS UNA PRUEBA DE UNA VISIÓN NO APOCALÍPTICA?}

Se pretende a menudo que la existencia misma de las parábolas -con frecuencia consideradas el modo más distintivo en que Jesús se expresó ${ }^{37}$ - mina también el paradigma dominante, en la medida en que no reflejan un estilo apocalíptico ni apuntan a una destrucción cósmica inminente ${ }^{38}$. En opinión de algunos autores, su «nueva» comprensión como «acontecimientos de lenguaje en que el Reino de Dios se convierte en una realidad presente ${ }^{39}$ no solo no tiene nada que ver con el juicio escatológico, sino que sería inconciliable con este.

Por una parte, sin embargo, existen parábolas que contienen en sí mismas imágenes escatológicas. Por ejemplo, la de la cizaña y el trigo (Mt 13,24-30, con su interpretación en Mt 13,36-43; EvTom 57), que compara el Reino de Dios a una situación en la que un hombre planta buena semilla y el enemigo lo llena de cizaña; el final del relato (en el que el señor dice a los segadores «Entresacad primero la cizaña y atadla en gavillas para quemarla; el trigo, almacenadlo en mi granero») evoca poderosamente el anuncio del juicio por el Bautista en Mt 3, 12. Otro caso es la parábola de la red (Mt 13,47-50; EvTom 8). Por consiguiente, el establecimiento de un contraste entre parábolas y escatología parece ser el fruto de una generalización apresurada.

No obstante, hay que reconocer que es cierto que la mayor parte de las parábolas no reflejan explícitamente una visión del mundo apocalíptica ni obligan a adoptarla. Ahora bien, esto no significa en modo alguno que excluyan una concepción apocalíptica. Las parábolas tienen una polivalencia que hace que su significa-

\footnotetext{
${ }^{36}$ Sin duda, sabemos aún menos de la hipotética comunidad de Q que de Jesús, por lo que resulta irónico querer utilizar aquella para entender a este.

${ }^{37}$ C. H. Dodd, The Parables of the Kingdom, New York, 1935, p. 1.

${ }^{38}$ Patterson, «The End of Apocalypse», pp. 38-40; Idem, The God of Jesus, p. 177; R. Funk, R. W. Hoover and the Jesus Seminar, The Five Gospels: the Search for the Authentic Words of Jesus, New York, 1993, p. 40 («The evidence of his parables and aphorisms shows that Jesus did not understand the rule of God to be the beginning of a new age, at the end of history, following a cosmic catastrophe»).

${ }^{39}$ Patterson, «The End of Apocalypse», p. 41. En el trasfondo de la argumentación actual se encuentra la interpretación existencial de las parábolas típica de N. Perrin, Jesus and the Language of the Kingdom, Philadelphia, 1976, esp. pp. 1-15; Idem, Rediscovering the Teaching of Jesus, New York, 1967, pp. 202s.
} 
do no sea una propiedad intrínseca de ellas, sino que depende más bien de los relatos en que se insertan, del marco narrativo en que se hallan (como lo muestra la presencia de las mismas parábolas en el Evangelio de Mateo y en el Evangelio de Tomás o la diversa interpretación de las mismas parábolas en la historia de la exégesis). De hecho, hay razones para creer que las palabras no fueron concebidas como enseñanzas, sino como un medio para ser usado en la enseñanza ${ }^{40}$. A esta luz, podría preguntarse incluso si tiene realmente sentido cuestionarse si tienen o no un sentido escatológico ${ }^{41}$.

Lo cierto es que cuando se observa que las parábolas no son útiles para la construcción de una imagen apocalíptica de Jesús, como si esto fuera un argumento contra esta imagen ${ }^{42}$, parece que se está cometiendo un contrasentido elemental, a saber, exigir que todo cuanto haya dicho un profeta escatológico tenga que tener un sentido directa y explícitamente apocalíptico. Es más, cabe pensar que quizás lo que se está cometiendo es una caricaturización de la posición contraria: se supone que lo que los defensores de la concepción apocalíptica están afirmando es que Jesús fue una suerte de monomaníaco obsesivo-compulsivo que únicamente pudo hablar del juicio o de la transformación final del mundo. Es obvio, sin embargo, que esta es una simplificación en la que nadie parece haber incurrido ${ }^{43}$.

\section{5. ¿TEXTOS EXTRACANÓNICOS COMO FUENTES PARA UN JESÚS NO APOCALÍPTICO?}

Entre las fuentes relativas a Jesús hay obras no incluidas en el canon. Una de las más célebres es el Evangelio de Tomás, un escrito copto (proveniente de la biblioteca de Nag Hammadi) del que se conocían ya algunos fragmentos griegos hallados en Oxirrinco en 1897 (P. Oxy. 1, 654, 655). Como colección de dichos, EvTom despertó desde muy pronto una gran expectación, siendo considerado por algunos investigadores como una obra de primera importancia para la recuperación de la figura de Jesús. La razón es que aproximadamente la mitad de sus logia son sentencias que no

\footnotetext{
40 «The parables (and aphorisms) were not intended primarily as teaching in themselves, but as instruments to be used in «teaching»» (J. Liebenberg, The Language of the Kingdom and Jesus. Parable, Aphorism, and Metaphor in the Sayings Material Common to the Synoptic Tradition and the Gospel of Thomas, Berlin New York, 2001, p. 529, cursivas originales).

${ }^{41}$ «Is it perhaps a case that one is asking of the parables (in questioning them as to whether they are eschatological or not) what they were never intended to answer?» (Liebenberg, The Language of the Kingdom, pp. 529-530).

42 «For whatever reason, the parables have been unhelpful in making the case for the apocalyptic Jesus» (R. J. Miller, «Theological Stakes in the Apocalyptic Jesus Debate», en J. S. Kloppenborg - J. W. Marshall, Apocalypticism, Anti-Semitism and the Historical Jesus. Subtexts in Criticism, London - New York, 2005, pp. 111-121, esp. 121).

43 «Not all of Jesus' ideas and activities derived from his eschatological beliefs. His conception of God's righteousness and mercy were grounded in the Scriptures and in traditional Jewish piety, informed by his own religious awareness» (R. H. Hiers, The Historical Jesus and the Kingdom of God. Present and Future in the Message and Ministry of Jesus, Gainesville, 1973, p. 113).
} 
poseen paralelos en la tradición sinóptica, y que por tanto pueden ser clasificadas en la categoría de ágrapha ${ }^{44}$. Es en este contexto como se comprende mejor la afirmación de algunos estudiosos según la cual EvTom refleja un estadio muy temprano de la tradición sobre Jesús en el que no hay presencia de escatología apocalíptica y, por tanto, pondría en cuestión la imagen de Jesús como un profeta escatológico; el material que permite elaborar esta imagen correspondería únicamente a desarrollos secundarios y tardíos de la tradición ${ }^{45}$. De este modo, EvTom confirmaría -se pretendelo que ya habría sugerido antes el estudio de $\mathrm{Q}^{46}$.

Prima facie, esta posición resulta prometedora, y además tiene el atractivo de parecer especialmente crítica: frente a la opción tradicional de privilegiar los Evangelios Sinópticos, la propuesta de recurrir a fuentes que no han sido incluidas en el canon y que han sido desechadas como heterodoxas produce la impresión de sofisticación académica, que permite liberarse de controles eclesiásticos y con ello de una visión dogmáticamente orientada. Ciertamente, la importancia de los escritos extracanónicos para un conocimiento menos sesgado y más completo de la historia plural del cristianismo primitivo es indiscutible. Ahora bien, ¿son útiles estos escritos para el conocimiento de Jesús, y en particular para subvertir la imagen del Jesús escatológico lograda a lo largo de dos siglos y medio de investigación?

La primera objeción a la que se enfrenta esta pretensión es la de que EvTom, lejos de ser un testimonio de un período originario privado de esperanzas apocalípticas, presupone $-\mathrm{y}$ critica- tales expectativas ${ }^{47}$. El texto conserva variantes de algunos de los dichos canónicos de contenido apocalíptico (cf. log. 57), mientras que reinterpreta otros en un sentido - sit venia verbo- desescatologizador. Así, por ejemplo, EvTom 113 presupone Lc 17, 21, pero mientras el contexto del dicho lucano (Lc 17, 22ss) constituye una profecía de acontecimientos apocalípticos, el logion 113 convierte al Reino de Dios (que aquí pasa a llamarse «Reino del Padre») en una realidad ya pre-

\footnotetext{
${ }^{44}$ Un ágraphon es un dicho atribuido a Jesús y no transmitido en los Evangelios canónicos. Solo una pequeña parte de estos ágrapha eran conocidos antes del descubrimiento de Nag Hammadi, mientras que el resto son inéditos.

45 «There is one element profoundly absent from it: apocalypticism. Most of Thomas's parallels to Q are to Kloppenborg's early, wisdom stratum in $\mathrm{Q}\left(\mathrm{Q}^{1}\right)$. There are a few parallels to sayings from the later apocalyptic stratum $\left(\mathrm{Q}^{2}\right)$, but where there are parallels to $\mathrm{Q}^{2}$, in each case tradition-historical analysis shows that the $\mathrm{Q}$ saying has been secondarily 'apocalypticized'. This is also true of Thomas-Mark parallels» (S. J. Patterson, «End of Apocalypse», p. 37); Idem, The God of Jesus, pp. 172-174; Idem, «Understanding the Gospel of Thomas Today», en S. J. Patterson - J. M. Robinson, The Fifth Gospel: The Gospel of Thomas Comes of Age, Harrisburg, 1998, p. 75; R. Funk, Honest to Jesus: Jesus for a New Millennium, New York, 1996, pp. 167-168. En este sentido, se ha afirmado que EvTom es «incompatible with the dominant paradigm of Christian origins» (R. Cameron, «Ancient Myths and Modern Theories of the Gospel of Thomas and Christian Origins», en R. Cameron - R. P. Miller (eds.), Redescribing Christian Origins, Atlanta, 2004, pp. 89-108, esp. 107).

${ }^{46}$ Cf. Patterson, «The End of Apocalypse», p. 37.

${ }^{47}$ «Even the Gospel of Thomas presupposes, and criticizes, a tradition of eschatological sayings of Jesus» (Koester, «Jesus the Victim», p. 7, n. 17); E. E. Popkes, «Von der Eschatologie zur Protologie: Transformationen apokalyptiker Motive im Thomasevangelium», en Becker - Öhler (eds.), Apokalyptik als Herausforderung neutestamentlicher Theologie, pp. 211-233. Esta es también la tesis de una importante monografía reciente; cf. A. D. DeConick, Recovering the Original Gospel of Thomas: A History of the Gospel and its Growth, London, 2005.
} 
sente. Dicho de otro modo, el autor del texto lleva a cabo una revisión deliberada de la tradición con el objeto de liberarla de la apocalíptica.

Esto conduce a una segunda y grave objeción, inextricablemente ligada a la anterior: la hipótesis de un Jesús no escatológico obliga a postular una hipótesis adicional sobre la génesis de EvTom que es innecesariamente complicada. En efecto, según el antiguo consenso la explicación de la génesis de un texto como EvTom es muy sencilla: 1) tradición del Jesús escatológico-apocalíptico;2) reacción contra esa imagen. A esta luz, EvTom es comprensible como una hermenéutica secundaria y espiritualizante (en línea con otros desarrollos conocidos en las corrientes cristianas primitivas) que reinterpreta la tradición con el objeto de contrarrestar la desilusión producida por el incumplimiento de las expectativas escatológicas de Jesús y sus discípulos. Por el contrario, la nueva visión exige una periodización trifásica: 1) tradición de un Jesús no apocalíptico; 2) aparición de una tradición apocalíptica; 3) reacción contra esa tradición. Resulta obvio que esta nueva hipótesis no solo crea nuevos problemas (¿de dónde provendría la aparición secundaria de una visión apocalíptica -que crea dificultades que habrán de ser enseguida neutralizadas- si no estaba ya en el propio Jesús?), sino que introduce una complicación innecesaria que la convierte en algo mucho menos plausible ${ }^{48}$.

Una tercera objeción es que la visión genérica de Jesús resultante de EvTom corresponde a una imagen deshistorizada que carece de toda plausibilidad contextual en la Palestina del primer tercio del s. I, y que se contrapone a lo que las fuentes disponibles permiten deducir acerca del personaje. Un ejemplo es la ausencia de aspectos demonológicos (referencias a Satán, espíritus malignos o exorcismos). En muy diversas fuentes sobre Jesús se halla todo un complejo de textos referidos a estos aspectos, que permiten deducir que este predicador carismático -a quienes sus contemporáneos presentaron como exitoso exorcista-comprendió su misión como un combate contra fuerzas satánicas. La masiva presencia de estos elementos brilla por su ausencia en EvTom. Este aspecto resulta comprensible, sin embargo, si el texto representa una hermenéutica secundaria destinada a cancelar los elementos apocalípticos de la tradición recibida.

Una cuarta objeción surge cuando se analizan en detalle los dichos de EvTom que presentan mayores visos de remontarse a Jesús, en virtud de cierto parecido en forma y contenido con las tradiciones sinópticas. El ágraphon que en más ocasiones ha sido propuesto como genuino es probablemente el log. 82 («Dijo Jesús: «Quien está cerca de mí está cerca del fuego, y quien está lejos de mí está lejos del Reino»») ${ }^{49}$. Pues

\footnotetext{
${ }^{48}$ Hasta tal punto tenemos aquí una hermenéutica secundaria, que no solo se descubre el patrón desescatologizador, sino que en esa estrategia algunos dichos se han convertido en algo forzado y rayano en el sinsentido. Compárese v.gr. Mt 13,47-50 con el log. 8 de EvTom.

${ }^{49}$ El logion está atestiguado también en Orígenes, Hom. Jer. 20, 3. Entre quienes aceptan su autenticidad se cuentan J. Jeremias, Unbekannte Jesusworte, Gütersloh, 1965², p. 70; J. Leipoldt, Das Evangelium nach Thomas. Koptisch und Deutsch, Berlin, 1967, pp. 18-19; A.J.B. Higgins, «Non-Gnostic Sayings in the Gospel of Thomas», Novum Testamentum 4 (1960), pp. 292-306, esp. 303ss; J.-B. Bauer, «Das Jesuswort: 〈Wer mir nahe ist»», Theologische Zeitschrift 15 (1959), pp. 446-450; Idem, «Echte Jesusworte? », en W. C. Van Unnik,
} 
bien, resulta irónicamente revelador que este logion presente a Jesús como un profeta con elevadas pretensiones que usa de modo consistente las nociones de «fuego» y «reino» en un contexto escatológico ${ }^{50}$, corroborando así su imagen como profeta apocalíptico $^{51}$. Así pues, el material más probablemente jesuánico de EvTom no parece inducir a modificar la imagen obtenida críticamente de los canónicos, sino que, más bien, la refrenda. El log. 82 resulta ser otro pequeño ladrillo en el muro escatológico contra el que se dan de bruces tantos exegetas ${ }^{52}$.

El intento de crear un Jesús subversivamente diferente del predicador escatológico deducible de los Evangelios canónicos muestra ulteriormente su inconsistencia cuando se advierte que EvTom sigue estrategias mutatis mutandis idénticas a las que despliega el Cuarto Evangelio. También este rechaza explícitamente la comprensión apocalíptica de logia de Jesús que debieron de suscitar perplejidad en miembros de la comunidad ${ }^{53}$, y representa un intento de espiritualizar la escatología apocalíptica, convirtiendo la muerte y la resurrección de Jesús en «la krísis del mundo» (Jn 12, 31) que pone fin al maligno reino de Satán ${ }^{54}$. De este modo, tanto el texto canónico como el apócrifo constituyen ejemplos de hermenéutica secundaria, que, lejos de permitir poner en cuestión el consenso tradicional, confirman la presencia del factor apocalíptico en la predicación de Jesús el galileo ${ }^{55}$.

Evangelien aus dem Nilsand, Frankfurt a. M., 1960, pp. 108-150, esp. 122-124; O. Hofius, «Unbekannte Jesusworte», en P. Stuhlmacher (ed.), Das Evangelium und die Evangelien, (WUNT 28), Tübingen, 1983, pp. 355-382, esp. 376-379; J.-É. Ménard, L'Évangile selon Thomas, Leiden, 1975, pp. 182-183; E. Broadhead, «An Authentic Saying of Jesus in the Gospel of Thomas?», New Testament Studies 46 (2000), pp. 132-149; Ch. W. Hedrick, «An Anecdotal Argument for the Independence of the Gospel of Thomas from the Synoptic Gospels», en H.-G. Bethge - S. Emmel - K. L. King - I. Schletterer (eds.), For the Children, Perfect Instruction. Studies in Honor of Hans-Martin Schenke on the Occasion of the Berliner Arbeitskreis für koptisch-gnostische Schriften's Thirtieth Year, Leiden, 2002, pp. 113-125, esp. 119-124; cf. también R. Trevijano, Estudios sobre el Evangelio de Tomás, Madrid, 1997, pp. 87-88.

${ }^{50}$ La imagen del fuego - destructor, pero también purificador- es un signo de la proximidad de Dios y/o del juicio en el Tanak y en el cristianismo primitivo, y es central en la predicación de Juan el Bautista (Mt 3, 10). La tradición evangélica atribuye a Jesús el uso de la imagen (Mc 9, 43; Mt 18, 8-9; 5, 22). La idea del Reino de Dios es central en la predicación de Jesús.

51 «The most authentic-looking piece of GThom does not support the image of Jesus as a non-eschatological sage» (Broadhead, «An Authentic Saying», p. 149).

52 Resulta elocuente que muchos autores que ven en el EvTom o en alguno de sus estadios tradición independiente, no utilicen el logion en sus reconstrucciones. Sobre su curiosa relegación en las obras de Crossan, Mack y Borg, cf. Broadhead, «An Authentic Saying», pp. 140 y 149, n. 27.

${ }^{53}$ Cf. Jn 2, 19-22; 21, 20-23.

${ }^{54}$ Jn 16, 8-11; 14, 30-31. Cf. J. Blank, Krisis: Untersuchungen zur johanneischen Christologie und Eschatologie, Freiburg i. B., 1964, pp. 281-294; Judith L. Kovacs, ««Now Shall the Ruler of This World Be Driven Out»: Jesus' Death as Cosmic Battle in John 12:20-36», Journal of Biblical Literature 114 (1995), pp. 227-247.

${ }^{55}$ De hecho, varios estudios sobre el solapamiento de material entre Mc y Q concluyen -a tenor de las tradiciones comunes en estas fuentes- la presencia de una fuerte esperanza escatológica en Jesús, unida a la creencia en un juicio final inminente; cf. B. T. Viviano, «The Historical Jesus in the Doubly Attested Sayings: An Experiment», Revue Biblique 103 (1996), pp. 367-410, esp. 406-407; W. Zager, Gottesherrschaft und Endgericht in der Verkündigung Jesu: Eine Untersuchung zur markinischen Jesusüberlieferung einschliesslich der Q-Parallelen, Berlin, 1996. 


\section{LOS DICHOS SOBRE EL «HIJO DEL HOMBRE», ¿CRUCIALES E INAUTÉNTICOS?}

Es sabido que un conjunto de logia en los Evangelios canónicos habla de la venida futura (y, en algunos casos, inminente) de una figura llamada «Hijo del hombre», una instancia escatológica que desempeñará un papel clave en el juicio final. De acuerdo con algunos autores, la imagen del Jesús escatológico es cuestionable ante todo en virtud de una doble constatación: a) Estos dichos son cruciales para la construcción de esa imagen ${ }^{56}, \mathrm{y}$ b) Existe un creciente consenso acerca de la inautenticidad (no proveniencia jesuánica) de esos dichos ${ }^{57}$.

Lamentablemente para el argumento, ninguno de estos dos asertos es cierto. Ante todo, no lo es que los dichos sobre el Hijo del hombre constituyan la piedra angular de la idea del Jesús escatológico, pues esta idea es omnipresente en la tradición evangélica ${ }^{58}$. De hecho, ni siquiera son determinantes para la idea de que Jesús esperó un fin inminente ${ }^{59}$, pues tal espera es testimoniada no solo en Mc 1, 15 y Mc 9, 1, sino también en otro abundante material (v. gr. Q 10, 9 y Lc 19, 11; Q 11, 2; Mc 14, 25; Q 11, 50-51; Q 12, 39-40, etc.). Tanto es así, que al construir su poderosa argumentación a favor de que Jesús predicó un juicio apocalíptico, Marius Reiser decidió no tomar en cuenta los dichos sobre el «Hijo del hombre», por considerarlo del todo innecesario ${ }^{60}$.

Además, no hay nada ni remotamente parecido a un consenso sobre la inautenticidad de estos dichos. Aunque ciertamente hay voces discrepantes, numerosos estudiosos competentes siguen opinando que (al menos una parte de) aquellos pasajes que hablan del Hijo del hombre que vendrá se remontan a Jesús ${ }^{61}$. De hecho, el gran nú-

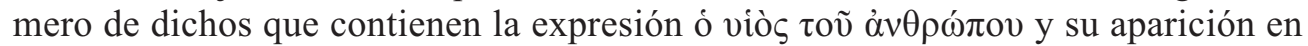
las diversas fuentes - Mc, Q, M, L, Juan, EvTom- inclinan a pensar que un equiva-

\footnotetext{
56 «If one did not think these sayings are authentic, most of the exegetical foundation for the eschatological Jesus would disappear» (Borg, «A Temperate Case», p. 52).

${ }^{57}$ Cf. 52-53, 84. El hecho que varios discípulos de Bultmann rechazaron la autenticidad de estos dichos es también un «argumento» de Patterson, «End of Apocalypse», pp. 38-39.

${ }^{58}$ Cf. supra, n. 6.

59 «Without the coming Son of man sayings, there is no reason to think of the kingdom of God as the imminent end of the world» (Borg, «A Temperate Case», p. 54). En la misma página Borg tiende a descartar alegremente la autenticidad de Mc 9, 1 y añade: «In any case, one verse is a slender thread upon which to hang a weighty case».

${ }^{60}$ «Angesichts der Fülle von Texten, die uns für das Thema der Gerichtspredigt Jesu zur Verfügung stehen, ist dies auch gar nicht notwendig. So lasse ich die Menschenworte zunächst ganz ausser acht» (M. Reiser, Die Gerichtspredigt Jesu. Eine Untersuchung zur eschatologischen Verkündigung Jesu und ihrem frühjüdischen Hintergrund, Münster, 1990, p. 190).

${ }_{61}$ V. gr. J. Becker, Jesus von Nazaret, Berlin, 1995, pp. 249-267; D. R. Catchpole, «The Angelic Son of Man in Luke 12:8», Novum Testamentum 24 (1982), pp. 255-265; J. Collins, «The Second Coming», Chicago Studies 34 (1995), pp. 262-274; A. Yarbro Collins, «Apocalyptic Son of Man Sayings», en B. A. Pearson (ed.), The Future of Early Christianity. Essays in Honor of Helmut Koester, Minneapolis, 1991, pp. 220-28; V. Hampel, Menschensohn und historischer Jesus, Neukirchen-Vluyn, 1990; Reiser, Die Gerichtspredigt Jesu; E. P. Sanders, The Historical Figure of Jesus, London, 1993, pp. 247-248; M. Casey, The Solution to the «Son of Man» Problem, London, 2007, passim.
} 
lente arameo (presumiblemente [בר [א][ש] se remonta a Jesús ${ }^{62}$. Por tanto, resulta metodológicamente arbitrario concluir de una percepción francamente subjetiva $-\mathrm{y}$, como vemos, fácilmente refutable- un supuesto estado de cosas, como lo hace Marcus Borg ${ }^{63}$.

Como ilustración de la fragilidad de la posición de quienes niegan en bloque la autenticidad de estos dichos ${ }^{64}$, pondré a continuación como ejemplo el caso de Mt 10 , $23 \mathrm{~b}$ («Pues en verdad os digo, no habréis acabado de recorrer las ciudades de Israel antes de que venga el Hijo del hombre»). Este texto pone un plazo a la llegada del Reino, por lo que su atribución a Jesús crearía serias dificultades teológicas. Borg niega su autenticidad, apelando a otros autores ${ }^{65}$. Entre las razones en contra de la historicidad se han aducido la carencia de atestiguación múltiple, el hecho de que parece corresponder a las circunstancias de la misión cristiana posterior, y que el establecimiento de un límite temporal a la llegada del Reino (resp. del Hijo del hombre) es comprensible como un dicho consolatorio de profetas cristianos a misioneros cristianos perseguidos. Hay, sin embargo, varias consideraciones que hablan a favor de la autenticidad del dicho ${ }^{66}:$ a) La limitación presupuesta del anuncio a Israel es consistente con la posición de Jesús (mientras que contradice la tendencia del redactor evangélico a adscribir a Jesús una misión entre los paganos) ${ }^{67}$; b) Parece poder aplicarse aquí el criterio de dificultad, pues se trata de una profecía incumplida ${ }^{68}$; c) El dicho -incluso si se contempla de manera unitaria el v. 23- no necesita ser situado en un contexto tardío de persecución generalizada, pues hay material verosímilmente auténti-

\footnotetext{
${ }^{62}$ Es también probable que Pablo haya conocido dichos sobre el «Hijo del hombre»; cf. B. A. Pearson, «A Q Community in Galilee?», New Testament Studies 50 (2004), 476-494, esp. 484-486.

${ }^{63}$ Este llega a hablar de «the disappearance of the coming Son of man sayings as authentic words of Jesus» («A Temperate Case», p. 53). Es instructivo comprobar cómo muchos exegetas dictaminan sobre la realidad a partir únicamente de sus propios deseos e ilusiones.

${ }^{64}$ Otro problema de la posición de Borg es que ha aducido que los análisis de Crossan refrendan su rechazo de la autenticidad de los dichos («Jesus and Eschatology», p. 85). Sin embargo, se ha señalado que Crossan no demuestra lo que pretende; cf. D. C. Allison, Jesus of Nazareth. Millenarian Prophet, Minneapolis, 1998, pp. 116-120.

${ }^{65}$ Cf. Borg, «A Temperate Case», p. 52. A los autores mencionados podríamos añadir ahora J. P. Meier, $A$ Marginal Jew, vol. II: Mentor, Message and Miracles, New York, 1994, pp. 339-341.

${ }^{66}$ En efecto, no es cierto que el logion sea casi unánimemente asignado a la situación postpascual. A favor se manifestó ya A. Schweitzer. Más recientemente, se expresan a favor, v. gr. C. Colpe, art. «ho huiós tô̂ anthrōpoû», Theologisches Wörterbuch zum Neuen Testament VIII (1969), pp. 403-481, esp. 439ss; M. Künzi, Das Naherwartungslogion Matthäus 10, 23. Geschichte seiner Auslegung, Tübingen, 1970, p. 180; V. Hampel, «Ihr werdet mit den Städten Israels», pp. 24-27; G. R. Beasley-Murray, Jesus and the Kingdom of God, Grand Rapids, 1986, 289-291; Allison, Jesus of Nazareth, pp. 148-151; U. Luz, El Evangelio según san Mateo, vol. II (Mt 8-17), Salamanca, 2001 (orig. alemán 1990), pp. 152-153, 160-161) no descarta tampoco que todo el v. 23 proceda de Jesús.

${ }^{67}$ «Nur als wirkliches Herrenwort kann Mt 10, 23 die am deutlichsten bei Mt hervortretende Tendenz, Jesus eine Wirksamkeit unter den Heiden zuzuschreiben, überdauert haben» (Colpe, «ho huiós tôิ anthrōpô̂», p. 439).

${ }^{68}$ «Erklärt man aber den Spruch für judenchristliche Gemeindebildung, dann ist nicht einzusehen, warum dieselbe Gemeinde, die ihn schuf, ihn nicht wieder fallengelassen hat, nachdem sich die Prophezeiung nicht erfüllt hatte [...] Nur als wirkliches Herrenwort also kann Mt 10, 23 [...] dem Anstoss, den man an ihm als unerfüllter Weissagung nehmen musste, nicht zum Opfer gefallen sein» (Colpe, «ho huiós tô̂ anthrōpồ», pp. 439-440).
} 
co que permite inferir la existencia de rechazo de los discípulos ya en vida de Jesús; el carácter simultáneamente promisorio y consolatorio del dicho resulta, pues, imaginable en boca de este ${ }^{69}$; d) El dicho presenta interesantes semejanzas formales y de contenido con otro material probablemente jesuánico: Mt 10, 23 b (al igual que Mc 9, 1 y 13, 30, los otros dos textos que establecen un tiempo límite a la venida del Reino) tiene una estructura literaria similar a Mc 14, 25. Tras una introducción enfática («en verdad os digo»), sigue una promesa o predicción relativa a que algo no sucederá (doble negación enfática oủ $\mu$ ń + futuro) antes de que el gran evento escatológico tenga lugar y sea experimentado por la(s) persona(s) que no realizará(n) la acción mencionada en la primera parte del dicho (conjunción temporal ع̌ $\omega \varsigma(\not \alpha v)+$ subjuntivo):

\begin{tabular}{|c|c|c|}
\hline Mc 14, 25 (Mt 26, 29) & Mt 10, 23b & Mc 9, 1 \\
\hline En verdad os digo: & En verdad os digo: & En verdad os digo: \\
\hline no volveré a beber & no habréis acabado & algunos de los que están aquí \\
\hline del fruto de la vid & las ciudades de Israel & no probarán la muerte \\
\hline hasta ese día en que & hasta que & hasta que \\
\hline lo beba nuevo & venga & vean venir en poder \\
\hline en el Reino de Dios & el Hijo del Hombre & el Reino de Dios \\
\hline
\end{tabular}

El paralelismo, que no se limita a aspectos formales, es realmente llamativo. Ahora bien, resulta que Mc 14, 25 es considerado -en virtud de diversos criterios- casi unánimemente auténtico, una consideración que se ve ulteriormente apoyada por la ausencia en el dicho de todo título o función cristológicos ${ }^{70}$. Ahora bien, ¿qué significa Mc 14, 25? Aunque una visión habitual es la de que Jesús está profetizando su muerte inminente en el contexto de la «última cena», esta interpretación es problemática. En efecto, el logion no parece haber pertenecido originalmente a su actual contexto $^{71}$. Esto no extraña, pues basta con leer tranquilamente el dicho para comprobar que en él la muerte no es mencionada ni explícita ni implícitamente ${ }^{72}$ : todo lo que dice es que Jesús no volverá a celebrar un banquete festivo sino cuando llegue el Reino de Dios. Lo que el texto sí comporta claramente es que Jesús esperaba la irrupción del

\footnotetext{
69 «Perhaps, as Schweitzer conjectured, Jesus and those around him already experienced the delay of the end and so a saying about living to see the fullness of time had a purpose even before Easter. Certainly the woes upon the cities in Galilee (Q 10: 13-15) show us that certain high hopes or expectations of Jesus fell to the ground» (Allison, Jesus of Nazareth, p. 150).

${ }^{70}$ Cf. v. gr. G. Theissen - A. Merz, Der historische Jesus: ein Lehrbuch, Göttingen, 1996, p. 233; Meier, A Marginal Jew, vol. II, pp. 302-30; Luz, Mateo, vol. II, p. 152, n. 17.

71 «Jesus' speaking in a generic fashion of his drinking of the fruit of the vine sounds a bit strange after the solemn identification of the wine with his blood. All this may indicate that Mark 14:25 was an isolated logion, necessarily connected by its content with the Last Supper, but not originally connected with the eucharistic words» (Meier, A Marginal Jew, vol. II, pp. 305-306).

${ }^{72} \mathrm{La}$ afirmación de Meier («this end-time prophecy involves a veiled reference to his death»: A Marginal Jew, vol. II, pp. 307 y 308) es gratuita, pues no se apoya en ningún argumento convincente.

73 "This saying is another bold declaration that the Kingdom is imminent" (B. S. Crawford, «Near Expectation in the Sayings of Jesus», Journal of Biblical Literature 101 (1982), pp. 225-244, p. 234).
} 
Reino en un futuro muy próximo ${ }^{73}$; aun no estableciendo una fecha fija, el dicho apunta a la llegada inminente del acontecimiento escatológico decisivo. Pues bien, la probable autenticidad de Mc 14, 25 aboga a favor de la autenticidad de los otros dichos, y por tanto de Mt $10,23 b^{74}$.

Si es así, hay buenas razones para pensar que otros dichos sobre el Hijo del hombre pueden ser auténticos. Uno de los presupuestos de Borg y otros es, por tanto, más que discutible. Pero -como hemos argumentado-, aun si se pudiera probar lo contrario, no sería significativo, pues la pretensión de que estos dichos son cruciales para construir una imagen apocalíptica de Jesús es, simplemente, errónea.

\section{7. ¿UNA «APOCALIPTIZACIÓN» PROGRESIVA DE LA TRADICIÓN EVANGÉLICA?}

Dado que la presencia del factor apocalíptico en la tradición evangélica es omnipresente y por tanto innegable, los autores que postulan un Jesús no apocalíptico pretenden explicar ese hecho como el resultado de un proceso en el cual los elementos apocalípticos habrían sido producidos en un período posterior al de la vida de Jesús, en virtud de una serie de acontecimientos que tuvieron lugar en los años 40 del s. I (la crisis provocada por el intento de Calígula de colocar una estatua suya, representado como Júpiter, en el Templo de Jerusalén) y más tarde en los años 60 (tensiones que cuajaron en la Primera Guerra Judía y en la devastación consiguiente) ${ }^{75}$.

El problema de esta posición -que reproduce ideas ampliamente sostenidas con anterioridad en la historia de la exégesis-no radica en que no pueda admitirse la influencia de tales hechos en algunos textos, como 2 Tes o Mc 13; el Evangelio de Mateo ciertamente constituye -en caso de aceptarse la hipótesis de la prioridad de Mc- una prueba del aumento de dichos referidos al juicio final ${ }^{76}$. El problema estriba, ante todo, en la unilateralidad de estas apreciaciones y en las conclusiones que de ellas pretende extraerse. Procesos que van en dirección directamente opuesta - en la de lo que podemos

${ }^{74}$ Resulta curioso, por tanto, que la autenticidad de Mt 10, 23 (y los otros dichos que siguen un patrón común a Mc 14, 25) sea negada de manera tan drástica por algunos exegetas. Meier -quien en su discusión de la autenticidad de Mt 10, 23 y los pasajes de Mc (A Marginal Jew, vol. II, pp. 339-347) no tiene en cuenta en absoluto las semejanzas formales y de contenido-llega a afirmar: «It has nothing to do with the historical Jesus» (ibidem, p. 340). Esto resulta tanto más llamativo cuanto que en Mc 13, 30 y Mt 24, 34 («En verdad os digo, no pasará esta generación sin que todo esto se haya realizado») -cuyo paralelismo formal y de contenido con los pasajes mencionados es obvio-se usa la expresión «esta generación», a favor de cuya probable autenticidad jesuánica el propio Meier argumenta en otro lugar (cf. Meier, A Marginal Jew, vol. II, p. 209, n. 134).

75 «Both of these events are likely to have intensified apocalyptic expectation among Jews, including Christian Jews [...] I locate the apocalyptic expectation of early Christianity in the post-Easter community» (Borg en Miller (ed.), The Apocalyptic Jesus, pp. 39-40).

${ }^{76}$ Cf. Reiser, Die Gerichtspredigt Jesu, p. 303; J. A. T. Robinson, «The New Look on the Fourth Gospel», en Idem, Twelve New Testament Studies, London, 1962, p. 103 («The Synoptists witness to a progressive apocalypticization of the message of Jesus, as recent study has shown, and as the Gospel of Matthew most forcibly illustrates»); D. C. Allison, Resurrecting Jesus. The Earliest Christian Tradition and its Interpreters, New York, 2005, pp. 63-68. 
denominar «desescatologización»- son claramente visibles en diversas trayectorias. Así, por ejemplo, mientras que la intensidad de la espera escatológica es obvia en 1 Tes, en cartas paulinas posteriores decrece paulatinamente, algo que ocurre aún más claramente en la literatura deuteropaulina o tritopaulina. Algo parecido es visible en la tradición evangélica: si -aceptando la prioridad de Marcos- comparamos Lucas con Marcos, advertiremos que material claramente apocalíptico es modificado y minimizado, algo que sucede con mayor claridad aún con el Cuarto Evangelio, en el que -por poner un solo ejemplo- la expresión «Reino de Dios / de los Cielos» se usa solo dos veces $(\operatorname{Jn} 3,3.5)^{77}$. Tanto es así, que muchos estudiosos de los orígenes cristianos han concluido que a lo que asistimos es - tanto en el tránsito de las cartas paulinas a la literatura deuteropaulina como en el material evangélico- a un debilitamiento de la intensidad escatológica a medida que el tiempo transcurre y las expectativas originales no se cumplen, y a una reinterpretación ${ }^{78}$. Si bien en algunas corrientes posteriores, como en el montanismo del s. II, se hará visible de nuevo una revivificación de esas esperanzas, estas se producirán precisamente como reacciones intermitentes al progresivo enfriamiento del entusiasmo que constituye la tónica general de las corrientes cristianas, y que la literatura de los primeros siglos testimonia. Este fenómeno responde a un patrón común de desarrollo en los movimientos milenaristas, en los que el fracaso de las expectativas obliga a generar reinterpretaciones de corte espiritualizante.

Por lo demás, de creer las pretensiones de Marcus Borg, la propia historia de la tradición sería incomprensible. En efecto, la incorporación de material apocalíptico resulta concebible si ya en la tradición previa existía este tipo de material, no solo en virtud del principio general según el cual lo semejante atrae a lo semejante, sino también si se tienen en cuenta las restricciones a la innovación que debe de haber supuesto el respeto por la tradición; a pesar del hecho obvio de que la tradición era maleable

\footnotetext{
${ }^{77}$ Resulta interesante comprobar que en los años 50 del s. XX un exegeta conservador, Ethelbert Stauffer, negó tajantemente el carácter apocalíptico de la predicación de Jesús aduciendo que ello le haría «nur einer von vielen Apokalyptikern seiner Zeit [...] und es wäre nicht recht einzusehen, warum gerade Jesus mit dieser Zukunftsbotschaft so starken Widerhall gefunden hat» (E. Stauffer, «Agnostos Christos. Joh. ii.24 und die Eschatologie des vierten Evangeliums», en W. D. Davies - D. Daube (eds.), The Background of the New Testament and Its Eschatology, Festschrift Ch. H. Dodd, Cambridge, 1964, pp. 281-299, esp. 281), y por tanto atribuye esa imagen a una apocaliptización posterior debida a la incomprensión de las comunidades cristianas. Con esta conjetura - «Vielleicht war Jesus, der historische Jesus, gar kein Apokalyptiker im hocheschatologischen Sinne, vielleicht haben nur die Zeitgenossen ihn so apokalyptisch verstanden, vielleicht hat erst die Jüngergemeinde nach Ostern ihm die hocheschatologischen Zukunftsworte in den Mund gelegt, die heute vielfach als die echtesten Jesusworte gelten» (ibidem, p. 282)-, llega Stauffer a la tesis, no por peregrina e implausible menos repetida hoy, de que el Evangelio de Juan es un testimonio de la naturaleza no apocalíptica de la predicación de Jesús.

78 «To some extent at least both types of literature solved the problem of the delay in the shift of aeons in a similar way, viz., by declaring that much of what had been awaited in the future was, in fact, to be understood as present reality» (P. J. Achtemeier, «An Apocalyptic Shift in Early Christian Tradition: Reflections on Some Canonical Evidence», Catholic Biblical Quarterly 45 (1983), pp. 231-248, p. 247); «The existence of such a similar development within two types of tradition that had no evident literary connections with one another (i.e., the Pauline materials with the gospel material) may point to a tendency more widespread and uniform within the primitive church than might have been suspected» (ibidem); "The later the writing, the lower its level of commitment to an imminent Apocalypse; the earlier the writing (i.e., Mark and, before him, Paul) the higher» (P. Fredriksen, Jesus of Nazareth, King of the Jews, Boston, 1999, p. 89).
} 
-así lo prueban las considerables variaciones perceptibles en las fuentes-, había limites para lo que podría agregarse, y es razonable esperar que lo que se añadiera tendiera a ser congruente con la imagen de Jesús ya presente en las fuentes anteriores ${ }^{79}$. Dado que esa tradición es productora de identidad comunitaria, una fidelidad básica a lo esencial de ella es esperable, y por consiguiente asimismo resultan esperables las resistencias a cualquier alteración significativa. De este modo, en las comunidades cristianas debe de haberse logrado una cierta estabilidad que habría impedido la substitución de ideas básicas por otras. En tales circunstancias, no resulta verosímil concebir la historia textual como una transición de una fase en la que los elementos apocalípticos están virtualmente ausentes a una nueva fase infestada de ellos.

\section{8. ¿DISCONTINUIDAD ENTRE EL BAUTISTA, JESÚS Y LA COMUNIDAD PRIMITIVA?}

Otro de los argumentos esgrimidos por Marcus J. Borg se basa en que la existencia de importantes diferencias entre Juan y Jesús es algo admitido por la práctica totalidad de estudiosos. A esta luz, por tanto, lo más natural resultaría pensar que existió asimismo discontinuidad entre ellos en el ámbito de su escatología apocalíptica. Ahora bien, dado que el carácter apocalíptico de Juan es innegable ${ }^{80}$, parece tener que deducirse su ausencia en el caso de Jesús ${ }^{81}$.

El primer problema de este argumento es su presupuesto. Es sin duda cierto que casi todos los exegetas neotestamentarios (y los teólogos) postulan la existencia de una discontinuidad significativa entre Juan y Jesús. La posición de los más eminentes intérpretes confesionales contemporáneos (J. P. Meier, J. D. Crossan, G. Theissen, J. D. G. Dunn) así lo prueba ${ }^{82}$. Ahora bien, en el ámbito científico, el recurso al

\footnotetext{
${ }^{79}$ Cf. N. A. Dahl, «The Problem of the Historical Jesus», en Idem, Jesus the Christ: the Historical Origins of Christological Doctrine, ed. by D. H. Juel, Minneapolis, 1991, p. 95; «Completely new creations are an exception, because what was added by the church in its tradition was closely associated with other transmitted materials, and extended them» (F. Hahn, «Methodological Reflections on the Historical Investigation of Jesus", en Idem, Historical Investigation and New Testament Faith: Two Essays, Fortress, 1983, p. 49).

${ }^{80}$ Así se deduce v. gr. de Mt 3 y Lc 3. De la ausencia de una atribución explícita de escatología al Bautista en Josefo no cabe extraer ningún corolario, ante todo porque esta desescatologización es una tendencia bien conocida en el historiador judío, que minimiza o elimina este aspecto para su auditorio romano; además, la noticia de Josefo sobre la capacidad del Bautista de enfervorizar a las multitudes y sobre la ejecución de este como un golpe preventivo debido al temor de Herodes Antipas a una revuelta armada adquiere sentido solo si se presupone una predicación escatológicamente cargada.

81 «Virtually every scholar agrees that Jesus and John differed in some significant ways. Why should we assume continuity of apocalyptic eschatology? The case needs to be made, not assumed» (Borg en Miller (ed.), The Apocalyptic Jesus, p. 39).

82 Esta posición tiene solera: «Die Dinge liegen doch wohl so, dass Jesus zwar von der apokalyptisch bestimmten Täuferbotschaft ausging, seine eigene Predigt aber nicht konstitutiv durch die Apokalyptik geprägt war, sondern die Unmittelbarkeit des nahen Gottes verkündigte. Wer diesen Schritt tat, kann nach meiner Überzeugung nicht auf den kommenden Menschensohn, die Wiederherstellung des Zwölfstämmevolkes im messianischen Reich und den damit verbundenen Anbruch der Parusie gewartet haben» (E. Käsemann, «Die Anfänge christlicher Theologie”, en Idem, Exegetische Versuche und Besinnungen, Göttingen, 1964, vol. II, p. 99).
} 
número de los partidarios de una posición no es un argumento válido. Parece detectarse aquí, pues, para empezar, la falacia del consensus gentium.

El segundo problema estriba en las excepciones a la regla. En efecto, diversos estudiosos competentes nunca han visto lo que la aplastante mayoría ve o dice ver, y han sostenido una continuidad esencial entre Juan y Jesús ${ }^{83}$. De hecho, recientemente se ha argumentado de modo detallado la existencia de una significativa continuidad fenomenológica entre el Bautista y Jesús ${ }^{84}$, en virtud a) del sometimiento de este al bautismo de aquel; b) de los numerosos paralelismos entre ambos predicadores testimoniados por la tradición evangélica ${ }^{85}$ (un dato tanto más elocuente y creíble a la luz de la tendencia cristiana a exaltar a Jesús sobre Juan); c) de la altísima consideración en que Jesús tuvo al Bautista ${ }^{86}$; d) del hecho de que las supuestas diferencias postuladas entre ellos ni son tan numerosas ni mucho menos cualitativamente tan relevantes como es costumbre señalar. Todo ello hace del todo implausible la opinión mayoritaria.

Un tercer problema radica en que la negación de la imagen apocalíptica de Jesús implica un postulado manifiestamente implausible, a saber, la existencia de un Jesús no escatológico entre dos magnitudes escatológicas (Juan el Bautista y la comunidad nazarena primitiva). La suposición de que un elemento que tiñó y determinó la religiosidad palestina, la del mentor de Jesús, la de sus discípulos y la del propio Pablo hubiera sido extraño a la predicación del galileo carece de verosimilitud ${ }^{87}$.

A la luz de las anteriores consideraciones, el «argumento» de Borg se vuelve del revés: la continuidad en las expectativas escatológicas es lo más verosímil, y quien quiera ponerla en duda es quien debe argumentarlo. Esta tarea, sin embargo, no ha sido -que sepamos- llevada a cabo ${ }^{88}$. Por el contrario, lo que sí se ha demostrado es que

${ }^{83}$ Cf. v. gr. A. Loisy, Jésus et la tradition évangelique, Paris, 1910, pp. 58-60 («Sa prédication ne différait pas sensiblement de celle du Baptiste»: p. 60); J. Klausner, Jesus of Nazareth. His Life, Times, and Teaching, London, 1925, p. 254 («His message closely resembled that of John the Baptist»); Ch. Guignebert, Jésus, Paris, 1933, pp. 185-6 ( «On peut, sans doute, estimer que la ressemblance affirmée par nos Évangiles entre les thèmes essentiels de la prédication de Jean et ceux de la prédication de Jésus prouve la parenté spirituelle des deux prophètes»); J. Montserrat Torrents, Jesús, el galileo armado, Madrid, 2007, pp. 87-88, 114 («La doctrina religiosa y moral atribuida a Jesús no rebasa la del Bautista»).

${ }^{84}$ Para una demostración de este aserto, cf. F. Bermejo, «Juan el Bautista y Jesús de Nazaret en el judaísmo del Segundo Templo: paralelismos fenomenológicos y diferencias implausibles», Ilu. Revista de Ciencias de las Religiones 15 (2010), pp. 27-56.

${ }^{85}$ Cf. Mc 11, 27-33; Lc 7, 24-27.29-35; cf. Lc 1, 5-25.57-80 y Lc 1, 26-38; 2, 1-52; Mt 3, 2 y 4, 17 (proclamación del mismo mensaje); Mc 6, 17-29 y Mc 14-15 (similar destino).

${ }^{86}$ Cf. esp. Lc 7, 24-26 = Mt 11, 7-10; Lc 11, $28=$ Mt 11, 11; Lc 7, 31-35 = Mt 11, 16-19.

87 J. D. Crossan, aun insistiendo en que «Jesus could have been a non-apocalyptic island in an apocalyptic sea», reconoce que la plausibilidad del postulado de la continuidad es uno de los puntos más sólidos de la posición apocalíptica (en Miller (ed.), The Apocalyptic Jesus, p. 122).

${ }^{88}$ La idea de un Jesús no escatológico opuesto a Juan es tan implausible que estudiosos como Borg y Crossan (siguiendo en esto la estela de otros, como E. Käsemann o M. Goguel) han postulado que Jesús aceptó originalmente la concepción apocalíptica del Bautista, y que solo más tarde la recusó a la luz de la muerte del Bautista, proponiendo «an anti-apocalyptic theology» (Crossan, The Historical Jesus, pp. 237-238). Sin embargo, resulta fácil mostrar que esta solución adolece también de arbitrariedad. Por una parte, sus defensores atribuyen todos los pasajes de sentido apocalíptico a la Iglesia primitiva, mientras que si Jesús fue en una fase determinada un pensador apocalíptico, algunos textos al menos podrían remontarse a él. Por otra, dado que la Crítica de las Formas estableció convincentemente que no es posible determinar el orden cronológico de los dichos atribuibles 
los presuntos «argumentos» a favor de la discontinuidad entre estos predicadores adolecen reiteradamente de inconsistencia ${ }^{89}$. Este hecho no puede sino provocar el más justificado escepticismo ante los apologistas de la discontinuidad.

\section{9. ¿CREENCIA DE JESÚS EN UN REINO DE DIOS YA «PRESENTE»? EL EJEMPLO DE Lc 17, 20}

Junto a una gran cantidad de material evangélico que prueba la creencia jesuánica en la irrupción del Reino de Dios en un futuro inminente, se encuentran unos pocos textos (Mt 12, 28/Lc 11, 20; Lc 17, 20; EvTom 113) que han sido utilizados para argumentar que Jesús el galileo creyó en la presencia del Reino en su propio tiempo. Algunos estudiosos intentan compatibilizar ambas tradiciones, mientras que otros -a pesar de la obvia diferencia cuantitativa ${ }^{90}$ - pretenden que este puñado de textos es el que expresa realmente las creencias del predicador galileo. En particular, Lc 17, 2021 es utilizado como un fundamento crucial del «Jesús no apocalíptico» ${ }^{91}$. Dado que este texto ha sido analizado en repetidas ocasiones con resultados que contradicen las pretensiones de quienes efectúan una lectura no escatológica del dicho ${ }^{92}$, me limitaré a algunas observaciones básicas.

a Jesús, sería perfectamente plausible sostener la hipótesis contraria, a saber, que la fase de identificación con el Bautista es la posterior, y no la primitiva (cf. Allison en Miller (ed.), The Apocalyptic Jesus, p. 85; «One might also contend for the opposite hypothesis: Jesus, because of disappointment in Galilee, reverted to John's proclamation of the wrath to come [...] One wonders how [...] those who defend a nonapocalyptic Jesus could argue forcibly against this take on things» (Allison, Constructing Jesus, p. 141). Un problema adicional de esta posición es que postula un desarrollo innecesariamente complicado e implausible en tres fases: 1) Jesús apocalíptico; 2) Rechazo de Jesús de la apocalíptica; 3) Rechazo, por los discípulos, del rechazo de Jesús. En lugar de explicar los testimonios textuales disponibles, el postulado de distintas fases en Jesús en relación con el Bautista introduce nuevas perplejidades y problemas.

${ }^{89}$ Cf. D. C. Allison, «The Continuity between John and Jesus», Journal for the Study of the Historical Jesus 1 (2003), pp. 6-27; Idem, Constructing Jesus, pp. 204-220; F. Bermejo, «Juan el Bautista y Jesús en la historiografía contemporánea: la persistencia del mito de la singularidad», Bandue 5 (2011), pp. 5-39. En este artículo he conjeturado la probable presencia de una agenda confesional: la insistencia -rayana en la obsesión- por descubrir diferencias entre los dos predicadores (a menudo con «razones» rocambolescas) sirve a la necesidad teológica de hacer de Jesús un sujeto totalmente incomparable en el judaísmo del Segundo Templo.

${ }^{90}$ Esto es algo que fue percibido ya en trabajos antiguos: «At the very best the passages which can be quoted in favor of the existing present kingdom are exceedingly few, while those which more naturally must be interpreted to refer to the future kingdom are all but constant» (Sh. Matthews, The Messianic Hope in the New Testament, Chicago, 1904, p. 80). Resulta significativa la presencia de tan escaso material seguro referido a la supuesta «presencia» del Reino, habida cuenta de que precisamente las comunidades primitivas hubieran estado muy interesadas en enfatizarlo, dado que para ellas algo importante se había manifestado en la persona y hechos de Jesús como cumplimiento de las profecías contenidas en el Tanak.

${ }^{91}$ Cf. v. gr. J. D. Crossan, The Birth of Christianity, San Francisco, 1998, p. 316; S. Patterson, «Con: Jesus Was Not an Apocalyptic Prophet», en Miller (ed.), The Apocalyptic Jesus, p. 75; Funk, Honest to Jesus, pp. 166ss. El pasaje parece haber sido fundamental para el Jesus Seminar; cf. B. B. Scott, «How Did We Get Here?», en Idem (ed.), Jesus Reconsidered: Scholarship in the Public Eye, Santa Rosa, 2007, pp. 47-64, esp. 59.

92 Por no remontarnos a Weiss, remito a algunas discusiones recientes: Frey, «Apokalyptik», pp. 76-77; Allison, Constructing Jesus, pp. 98-116; Piñero, «Notas críticas», passim. 
Una consideración preliminar necesaria es que, si bien Lc 17, 20-21 suele ser considerado auténticamente jesuánico ${ }^{93}$, hay (autorizadas) voces discrepantes ${ }^{94}$. La razón no es solo que el pasaje es susceptible de ser interpretado como una reacción espiritualizante al denominado «retraso de la Parusía», sino también que la expresión $\mu \varepsilon \tau \grave{\alpha}$

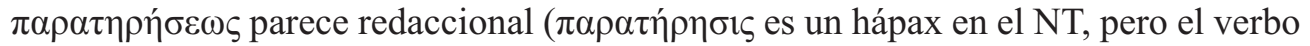
$\pi \alpha \rho \alpha \tau \eta \rho \varepsilon ́(\omega \text { es editorial en Lc) })^{95}$.

Una segunda observación elemental es que, aun si se acepta la proveniencia jesuánica de Lc 17, 20-21, su significación precisa no es en absoluto clara. De hecho, según algunos afamados intérpretes (como R. Bultmann o J. Jeremias), el pasaje manifiesta que el Reino de Dios aparece repentinamente; según otros ${ }^{96}$, significa que el Reino está al alcance de los oyentes, dentro de su radio de acción ${ }^{97}$. En este tipo de interpretaciones, el texto no excluye una escatología de futuro ${ }^{98}$. En todo caso, debería ser evidente que el carácter problemático del dicho ${ }^{99}$ hace metodológicamente improcedente erigirlo en fundamento de una interpretación.

Un tercer problema es que, aun aceptando a efectos de la discusión que el sentido de Lc 17, 20-21 se refiere de algún modo a una presencia del Reino, su status relativo en la predicación de Jesús no es en absoluto claro. Un resultado seguro de la escuela de la Crítica de las Formas es que ignoramos el contexto específico en que Jesús pronunció sus dichos ${ }^{100}$; ahora bien, si el contexto determina el significado, ¿cómo es posible estar seguros de que dichos -en sí mismos, como hemos visto, de difícil interpretación- refutan la bien atestiguada espera escatológica? Por ejemplo, si los escasos dichos a los que nos referimos fueron pronunciados en un contexto especialmente polémico, probablemente no tienen una validez general y no testimonian una creencia firme en la «presencia» del Reino, o pueden contener hipérbole. Por otra parte, cabe tener en cuenta la interpretación que el sensato Johannes Weiss efectuó a finales del s. XIX. Para él, no fueron sino dichos ocasionales que expresan el entusiasmo de Jesús: al igual que, cuando la tormenta se aproxima, uno puede decir que «viene

\footnotetext{
93 N. Perrin, Rediscovering the Teaching of Jesus, New York, 1967, 68-74.

${ }^{94}$ Cf. Sanders, The Historical Figure of Jesus, p. 177. Lo mismo ocurre con Mt 12, 28/Lc 11, 20; cf. H. Räisänen, «Exorcisms and the Kingdom: Is Q 11, 20 a Saying of the Historical Jesus?», en Idem, Challenges to Biblical Interpretation. Collected Essays 1991-2001, Leiden, 2001, pp. 15-36.

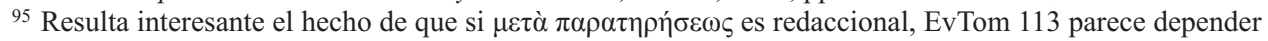
de Lucas; cf. Allison, Constructing Jesus, p. 102.

96 Cf. Beasley-Murray, Jesus and the Kingdom, pp. 102-103.

${ }^{97}$ Para una interpretación diferente de $\dot{\varepsilon} v \tau$ ò $\varsigma \dot{~} \mu \tilde{\omega} v \mathrm{cf}$. T. Holmén, «The Alternatives to the Kingdom:

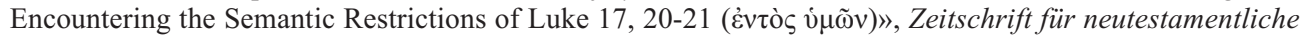
Wissenschaft 87 (1996), pp. 204-229.

${ }^{98}$ Algo parecido cabe decir de Mt 12, 28/Lc 11, 20. Sobre la ambigüedad del aoristo ě $\varphi \theta \alpha \sigma \varepsilon v$ (que podría

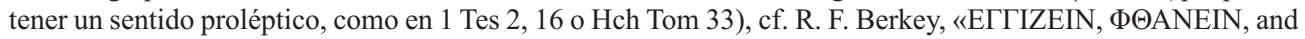
Realized Eschatology», Journal for the Study of the New Testament 3 (1979), pp. 177-187.

${ }^{99}$ Como ya señaló Weiss, que se refirió a «diese ganz dunkle Stelle» (Die Predigt Jesu, p. 86). El propio Patterson se refiere a «its inscrutable final phrase» (S. J. Patterson, «An Unanswered Question: Apocalyptic Expectation and Jesus' Basileia Proclamation», Journal for the Study of the Historical Jesus 8 (2010), pp. 6779, p. 71).

${ }^{100}$ De hecho, debería tenerse en cuenta que el autor de Lc 17, 20-21 y el de EvTom 113 han dado un marco diferente para el mismo dicho.
} 
una tormenta», pero también puede decir prolépticamente «la tormenta está ahí / ha llegado», Jesús habló en ocasiones del Reino de Dios como si estuviera presente; en otras palabras, los dichos mencionados reflejan únicamente un matiz en la actitud del visionario profético, pero no expresan una concepción escatológica diferente de su tensión escatológica testimoniada por doquier en la tradición evangélica, y sería por tanto un error garrafal convertirlos en el fundamento de una doctrina distinta ${ }^{101}$.

Un cuarto problema para los defensores del «Jesús no escatológico» es que -tal como Jacques Schlosser ha señalado ${ }^{102}$ - un texto como Lc 17, 20-21 podría estar utilizando la frecuente construcción semítica de la negación relativa o dialéctica, en que el énfasis cae en el segundo miembro del dicho sin realmente anular el primero. La frase «el Reino de Dios no viene $\mu \varepsilon \tau \grave{\alpha} \pi \alpha \rho \alpha \tau \eta \rho ́ \sigma \varepsilon \omega \varsigma$ (= con fenómenos que pue-

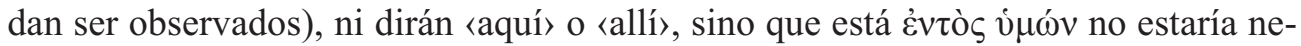
gando realmente que el Reino vendrá del modo al que se refiere la primera parte del mensaje, sino solo enfatizando la información proporcionada en la segunda parte (sea lo que fuere lo que esta significa) ${ }^{103}$. Ahora bien, es precisamente una exclusión antitética, en la que la primera parte del mensaje ha de ser tomada literalmente, lo que la imagen no escatológica de Jesús presupone.

Una quinta objeción es que, aun si se pudiera atribuir a Jesús la creencia en que el Reino está presente (hay que añadir, como ya es habitual entre los exegetas, «de algún modo»), esto no implica en modo alguno la ausencia de su creencia en la venida futura del Reino de Dios. En primer lugar, el redactor evangélico colocó el dicho en un contexto que contiene toda una serie de advertencias frente a la catástrofe escatológica inminente ${ }^{104}$. Además, la creencia de que el Reino ha llegado no implica que haya llegado plena y cabalmente ${ }^{105}$. A menos que creamos que Jesús fue un individuo mentalmente perturbado, no pudo pensar que el Reino había llegado, porque las fuentes testimonian que él mismo - por entusiasta y visionario que haya sido- fue consciente del mal prevaleciente por doquier en su mundo (hambre, injusticia, violencia,

\footnotetext{
101 «Wenn die Wetterwolken aufziehen und die Blitze schon am Horizont zucken, so mag man sagen: es kommt ein Gewitter. Man kann aber auch proleptisch sagen: es ist Gewitter. Oder, wenn die Sonne zum ersten Mal wieder warm und leuchtend scheint und die ersten Knospen schwellen, so wird man im Allgemeinen sagen: der Frühling ist nahe. Aber wer will dem sehnsüchtigen Gemüt wehren, wenn es jauchzend schon in diesem ersten Zeichen den ganzen Frühling begrüsst, als sei er schon da mit all seiner Herrlichkeit. Da entscheidet das Temperament und die Frische der Empfindung. Und so ist es denn nur eine Steigerung der allgemeinen Gewissheit, wenn Jesus hier und da in prophetischer, freudiger Begeisterung die kurze Spanne des Wartens überspringt, als ob er bereits am Ziele sei. Es handelt sich um eine Nuance in der Stimmung, nicht um verschiedene dogmatische Anschauungen» (Die Predigt Jesu, pp. 69-70; cf. ibidem, pp. 69-96). Véanse, en este sentido, las apreciaciones de un estudioso contemporáneo: «Die Tatsache, dass Jesu Worte von der Gegenwart der $\beta \alpha \sigma ı \lambda_{\text {cí } \alpha}$ grundlegend auf die futurische Erwartung, auf deren Aufrichtung zurückbezogen sind, widerrät allen Versuchen, in diesen Gegenwartsaussagen eine grundsätzliche Distanznahme von den Traditionen der frühjüdischen Apokalyptik zu sehen» (Frey, «Apokalyptik», p. 79).

102 J. Schlosser, Le Règne de Dieu dans les dits de Jésus, vol. 1, Paris, 1980, pp. 212-213.

103 «Compris comme négation relative le premier member de notre logion, malgrés les apparences, ne nie pas la venue future du Règne, il sert seulement à mettre en relief le membre positif, pointe de l'ensemble» (Schlosser, Le Règne de Dieu, p. 213).

104 Cf. v. gr. G. Puente Ojea, Fe cristiana, Iglesia, Poder, Madrid, 1991, 134-136.

105 Cf. Beasley-Murray, Jesus and The Kingdom, pp. 75-80.
} 
sufrimiento), algo por definición incompatible con la instauración definitiva del Reino de Dios. Por ejemplo, el hecho de que Jesús creyera en la existencia activa de los demonios, y de que estos tenían todavía que ser expulsados del mundo, es clara prueba de que percibía que el Reino aún no ha llegado -o, al menos, no plenamente- ${ }^{106}$.

Las anteriores reflexiones, por elementales que sean, deberían bastar para mostrar que todo edificio levantado sobre Lc 17, 20-21 (y, a fortiori, sobre el resto de pasajes aducidos en el sentido de una presunta creencia fundamental de Jesús en la presencia del Reino de Dios) será solo - para emplear una imagen evangélica- una casa edificada sobre arena.

\section{0. ¿ÉXITO DEL CRISTIANISMO COMO PRUEBA DE LA AUSENCIA DE UNA ESCATOLOGÍA FRACASADA?}

Con el objeto de mostrar la ausencia de un Jesús apocalíptico, John Dominic Crossan ha argumentado que si este hubiera existido, uno esperaría encontrar en las fuentes testimonios de una constante desbandada de individuos defraudados en sus expectativas: el incumplimiento de las profecías habría llevado al abandono masivo de la comunidad. Dicho de otro modo: el éxito de las comunidades cristianas sería incompatible con el fracaso de Jesús, pero este fracaso habría tenido lugar si el galileo hubiera mantenido una escatología de corte apocalíptico ${ }^{107}$.

¿Qué decir de este argumento? Ante todo, resulta extrañamente ingenuo esperar que las fuentes cristianas nos ofrezcan una descripción objetiva de las reacciones negativas y defecciones que se habrán producido en las primeras comunidades; dado que esas fuentes son de naturaleza obviamente apologética, lo esperable más bien es que hayan minimizado en lo posible los descorazonadores fenómenos de decepción y desilusión que tienen que haberse producido. De hecho, curiosamente esta misma estrategia es visible en el propio texto de Crossan, que se refiere a «tiny ripples of surprise» en la tradición textual. Lo cierto, sin embargo, es que hay rastros más que suficientes ya en el Nuevo Testamento -Evangelios, Cartas paulinas, Apocalipsis, Cartas «católicas» - de decepción por el incumplimiento de las expectativas escatológicas. Textos como Lc 19, 11 (según el cual no Jesús, sino solo otros «creían que el Reino de Dios iba a manifestarse inmediatamente»); Jn 21, 20-23 (a diferencia de la interpretación efectuada por los discípulos, Jesús no habría declarado que uno de sus discípulos es-

\footnotetext{
106 «Were the Kingdom of God fully present, obviously exorcisms would no longer be needed» (Räisänen, «Exorcisms and the Kingdom», p. 21). El Reino de Dios «is a peculiar state of things when God is reigning without any opposition, neither by man, nor by the evil spirits [...] something most desirable, an estate of complete happiness» (E. von Dobschütz, The Eschatology of the Gospels, London, 1910, pp. 94-95, 96).

107 «As the decades of the first hundred years passed without millenarian consummation, tiny ripples of surprise appear on the surface of the tradition, but I see no evidence of profound doubt or massive loss of faith. I do not find what I might have expected: profound defensive strategies, desperate explanatory interpretations, but, despite them, slow and steady attrition in faith. I would have expected, in other words, a steadily decreasing number of converts and communities and I find instead a steadily increasing number of both converts and communities»» (J. D. Crossan, «Con: Jesus Was Not an Apocalyptic Prophet», en Miller (ed.), Apocalyptic Jesus, p. 54).
} 
taría vivo hasta que Jesús retornase en su Parusía) ${ }^{108} ; 1$ Tes 4, 13 - 5, 11 (la muerte de algunos miembros de la comunidad sin que se haya producido la esperada salvación suscita una aflicción y pérdida de esperanza que Pablo debe contrarrestar); Ap 6, 10 (en una visión, los mártires preguntan al Señor cuándo se les hará justicia y se vengará su muerte); 2 Pe 3, 1-10 (hombres burlones se mofan de la promesa de la venida gloriosa del Señor, pero para este mil años son como un día) son solo algunos ejemplos muy elocuentes -nada «minúsculos» o «insignificantes»-acerca de cuál debió de ser el verdadero alcance de tal decepción, y de que sin duda hubo adherentes a la religión que reaccionaron con escepticismo (y probablemente con la deserción) al fracaso de las esperanzas escatológicas de Jesús y de sus primeros seguidores.

Por otra parte, la objeción señalada por Crossan presupone asimismo una visión sorprendentemente ingenua y simplista de los factores que condicionan la continuidad de la adhesión de los sujetos a la creencia religiosa en un contexto de falsación de expectativas o de contenidos veritativos de su creencia, y de los modos en que se producen las reacciones a estos hechos. En efecto, tal como muestra el análisis de fenómenos religiosos tanto antiguos como modernos ${ }^{109}$, lo que para una perspectiva externa constituye un inequívoco fracaso de expectativas a menudo no entraña, para los miembros de la comunidad religiosa implicada, la disolución o el abandono de la fe, sino que más bien provoca toda una serie de estrategias de inmunización, redundando en ocasiones incluso en el fortalecimiento de la identidad del grupo. Esto es claramente perceptible tanto en lo sucedido con textos apocalípticos como con movimientos como los Testigos de Jehová o los adventistas.

Las estrategias de inmunización susceptibles de ser puestas en funcionamiento son múltiples: puede interpretarse el incumplimiento de las expectativas como necesidad de proceder a una espera vigilante, pretenderse que las expectativas han sido cumplidas parcialmente o de un modo diferente al esperado (por ejemplo, en una esfera espiritual, empíricamente imperceptible), reinterpretarse las expectativas difiriendo su cumplimiento a un futuro aún más lejano (y a menudo atribuyendo el fracaso de las anteriores a la incomprensión de los propios creyentes), transferirse la responsabilidad del incumplimiento a la conducta indigna o pecaminosa de la comunidad que lo esperaba, etc. ${ }^{110}$. Significativamente, todas estas estrategias de inmunización son perceptibles en la literatura cristiana primitiva, ya en los diversos escritos del Nuevo Testamento, como se puede deducir de lo ya expuesto ${ }^{111}$.

Las razones de este hecho son fácilmente comprensibles cuando se tiene en cuenta la complejidad de los fenómenos religiosos. En cuanto fenómenos sociales, estos no se circunscriben a los contenidos veritativos o a las expectativas que pueden

\footnotetext{
108 En el trasfondo hay, obviamente, un dicho como Mc 9, 1.

${ }^{109}$ Cf. R. P. Carroll, When Prophecy Failed: Cognitive Dissonance in the Prophetic Traditions of the Old Testament, New York, 1979; J. R. Stone (ed.), Expecting Armageddon: Essential Readings in Failed Prophecy, New York, 2000.

${ }^{110}$ Cf. v. gr. J. F. Zygmunt, «When Prophecy Fails: A Theoretical Perspective on the Comparative Evidence», American Behavioral Scientist 16 (1972), pp. 245-268.

111 Para una exposición sistemática de este aspecto, cf. Allison, Constructing Jesus, pp. 149-153.
} 
eventualmente ser -para emplear la terminología de Karl R. Popper- susceptibles de falsación. En la medida en que la religión es normalmente vivida por los sujetos de un modo que implica complejas relaciones intersubjetivas y poderosos compensadores psicológicos y emocionales -a veces incluso económicos-, los contenidos doctrinales son solo un factor entre otros, y a menudo no determinante, a la hora de decidir la inclusión en un grupo ${ }^{112}$, y por tanto también a la hora de evaluar la satisfacción que produce la adhesión cuando uno se plantea -conscientemente o nola posibilidad de una defección. Y esto, a su vez, permite comprender que la percepción de las inconsistencias puede no tener los mismos resultados en sujetos diferentes, también debido a que las inconsistencias pueden ser percibidas con distinta intensidad por los distintos sujetos, en función de diversas circunstancias y del sentido de identidad que producen. Así pues, no es la profecía incumplida qua talis lo que provoca irremediablemente el desencanto entre los creyentes y el abandono de la creencia, sino las condiciones personales y sociales en que el incumplimiento se percibe lo que determina el impacto que en última instancia se produce sobre las creencias $^{113}$. Resulta mucho más fácil asumir y neutralizar las dificultades (y aun las contradicciones) epistémicas generadas en un sistema cuando la integración en ese sistema proporciona a los sujetos evidentes ventajas adaptativas. Lo que esto implica acerca del puesto real que a menudo ocupa el interés por la «verdad» en los sistemas religiosos y en quienes forman parte de ellos es demasiado evidente como para merecer aquí ulterior tratamiento.

A la luz de estas reflexiones, resulta obvio que del éxito de la propagación del cristianismo -por lo demás, muy comprensible en la perspectiva de la sociología y la historia de las religiones- no puede inferirse absolutamente nada respecto al carácter de las perspectivas escatológicas de Jesús el galileo, el referente judío de los fenómenos cristianos. La existencia de un obvio fracaso objetivo de las expectativas escatológicas de un sujeto que esperó una transfiguración inminente del mundo es -como muestra de modo recurrente la historia, y en particular la de los propios fenómenos cristianos, intermitentemente productores de esperanzas milenaristas y apocalípticas- perfectamente compatible con la pervivencia y la propagación de las comunidades generadas en virtud de las creencias compartidas acerca de tal sujeto.

\footnotetext{
112 Cf. R. Stark - W. S. Bainbridge, Acts of Faith: Explaining the Human Side of Religion, Berkeley, 2000, pp. 114-138.

113 Esto contribuye a explicar también, por supuesto, las distintas reacciones de los estudiosos ante los resultados obtenidos en la investigación sobre Jesús el galileo. Como he señalado en otra parte, varios de estos resultados contradicen la imagen tradicional de Jesús presentada por las comunidades cristianas (cf. Bermejo, «The Fiction of the Three Quests», p. 246, n. 103). Aunque unos pocos estudiosos extraen los corolarios de este hecho («Orthodox Christology is difficult to reconcile with truth»: M. Casey, From Jewish Prophet to Gentile God. The Origins and Development of New Testament Christology, Cambridge, 1991, p. 176; «Those who subscribe to Nicea should be anxious, for the historical Jesus did not think of himself what they think of him»: D. C. Allison, The Historical Christ and the Theological Jesus, Grand Rapids, 2009, p. 89), son siempre una exigua minoría. La razón de este fenómeno parece ser los compromisos confesionales y existenciales, cuando no directamente pastorales, de la mayor parte de exegetas y estudiosos neotestamentarios.
} 


\section{1. ¿FUE JESÚS MALENTENDIDO POR SUS DISCÍPULOS?}

Una de las razones que permiten concluir a muchos que Jesús fue un predicador con hondas convicciones apocalípticas consiste en el testimonio relativo a las expectativas de sus discípulos, por ejemplo respecto a la llegada inminente del Reino y al carácter políticamente liberador del propio Jesús (cf. v. gr. Lc 24, 21: «Nosotros esperábamos que él era el que había de liberar a Israel»; Hch 1, 6: «Señor, ¿en este tiempo vas a restablecer el reino a Israel?»). Si esto es lo que creían sus discípulos, hay que suponer que es el maestro quien transmitió estas ideas. Un modo de cortocircuitar esta línea de razonamiento consiste en sostener que Jesús fue malinterpretado por sus propios discípulos. Y es precisamente esta idea la que encontramos en algunos fautores de la imagen del Jesús no escatológico ${ }^{114}$.

El primer problema con esta idea es que nolens volens presupone, sea que la predicación de Jesús era especialmente complicada (como para haber sido malentendida por todos sus discípulos), sea que Jesús se caracterizó por su especial inepcia como maestro, o ambas cosas. Ahora bien, no hay ninguna razón para aceptar ninguno de estos supuestos. La predicación religiosa de un visionario sin una cultura especial no puede haber sido muy sofisticada o abstrusa, y desde luego no hay el menor indicio en la tradición de una enrevesada complejidad doctrinal que exigiera una inteligencia o una educación especial ${ }^{115}$; los discípulos de Jesús, sin duda, podían entenderle muy bien. Por otra parte, la imagen de Jesús que nos transmite la tradición -aun teniendo en cuenta y descontando el plus de inflación que suelen experimentar los individuos objetos de veneración- es la de un predicador y comunicador hábil, no la de un sujeto torpe e inepto para expresar con suficiente claridad su (urgente) mensaje.

Un segundo problema es que la idea de una flagrante malinterpretación del mensaje presupone una discontinuidad entre las ideas del maestro y las de sus discípulos que resulta del todo implausible en vida del primero. Sin duda, Jesús cometió errores garrafales tanto en algunas de sus predicciones como de sus elecciones (si la historia de Judas Iscariote merece credibilidad, Jesús cometió el error de elegir como discípulo a un individuo que acabaría traicionándolo), pero que ignorara que los in-

\footnotetext{
114 Según Robert Funk, Jesús «can hardly have shared the apocalyptic outlook of John the Baptist, Paul, and other members of the early Christian community [...] We can understand the intrusion of the standard apocalyptic hope back into his gospel at the hands of his disciples, some of whom had formerly been followers of the Baptist: they had not understood the subtleties of Jesus' position, they had not captured the intensity of his vision, and so reverted to the standard, orthodox scenario once Jesus had departed from the scene») (Honest to Jesus, p. 168). Esto supone retomar una idea expresada a menudo en la exégesis y la teología cristianas: "It would be understandable that the first Christians should not at the early stages grasp all that was entailed in his teaching» (T. F. Glasson, Jesus and the End of the World, Edinburgh, 1980, p. 109). Obsérvese que Jn 2, 24 («Pero Jesús no se confiaba a ellos porque los conocía a todos») fue empleado ya por Stauffer de modo implausible (cf. supra, n. 77).

115 De hecho, cabe preguntarse si tal atribución inconsciente a la predicación del personaje de una complejidad mucho mayor de la testimoniada por las fuentes no estará condicionada precisamente por la creencia en la especial naturaleza ontológica del personaje, o no será quizás también una retroproyección a Jesús de las sutilezas de la tradición teológica cristiana.
} 
dividuos que había congregado para ayudarle a predicar su mensaje -y a los que envió en misión ${ }^{116}$ - fueran tan obtusos e incapaces de entenderle, y por tanto de propagar su mensaje de modo fiable, resulta francamente inverosímil. Esto supone atribuir a Jesús un grado de falta de realismo y desconocimiento de la naturaleza humana que no parece compatible con lo que la tradición nos dice del personaje.

Un tercer problema estriba en que la estrategia de atribuir incomprensión a los discípulos aparece ya en los propios textos evangélicos, en los cuales no obstante presenta todo el aspecto de ser un dispositivo crasamente apologético y/o polémico. Así, por ejemplo, Lc 19, 11 (Jesús «les contó otra parábola [...] y ellos creían que el Reino de Dios iba a manifestarse inmediatamente») supone una distinción en las expectativas escatológicas de Jesús y sus oyentes, achacándola a una malinterpretación; Lc 24, 21 y Hch 1, 6 presuponen esta distinción, en la medida en que la expectativa de los discípulos consiste en que Jesús es un liberador que restaurará el reino a Israel, por lo cual deben ser amonestados y corregidos por el Jesús resucitado. Jn 21, 22-23 supone una malinterpretación de un dicho como Mc 9, 1. El artificio del 1lamado «secreto mesiánico» en el Evangelio de Marcos y varios pasajes del Cuarto Evangelio (Jn 12, 16; 21, 23) refrendan la extensión de esta estrategia. El carácter de racionalización secundaria que transpiran todos estos textos apunta a que carecen de toda plausibilidad histórica ${ }^{117}$.

Cuando se toman en consideración las precomprensiones en juego, así como la ausencia de sentido crítico que entrañan, uno puede concluir sin temor a equivocarse que el presunto argumento basado en la incomprensión de los discípulos carece de toda plausibilidad, constituyendo más bien un síntoma de la aporía en que se hallan los estudiosos que necesitan recurrir a él.

\section{CONCLUSIONES Y REFLEXIONES ULTERIORES}

El examen de los argumentos esgrimidos por los defensores modernos de la imagen no apocalíptica de Jesús nos ha permitido demostrar que todos ellos adolecen de una llamativa fragilidad: ni uno solo se ha mostrado convincente, por lo que su acumulación (hemos identificado y criticado nada menos que una decena) resulta vana. Por muchos que sean los libros que los contengan y las voces que los proclamen -aunque estas están muy lejos de haber producido nada remotamente parecido a un «consenso»-, carecen de fuerza para servir de ariete contra la fortaleza escatológica le-

\footnotetext{
${ }^{116}$ Cf. v. gr. Mc 6, 7-12; 9, 14-18; Mt 10, 1-23; Lc 9, 1-10.52; 10, 1-17. Cabe tener en cuenta también que el principio de la convergencia del discípulo y el maestro (cf. Mt 10, 24-25; Lc 6, 40; Jn 13, 16; 15, 20) debe de haber funcionado, de modo que unirse al ministerio de Jesús implicaba repetir (al menos con cierta fidelidad) lo que él proclamaba. Para una detallada argumentación en este sentido, cf. R. Riesner, Jesus als Lehrer: Eine Untersuchung zum Ursprung der Evangelien-Überlieferung, Tübingen, 1981, pp. 453-475. Según Lc 10, 16, «El que a vosotros oye, a mí me oye».

${ }^{117}$ Algo parecido cabe decir de la fundamental corrección de Jesús a sus discípulos en los logia 51 y 52 de EvTom.
} 
vantada en la obra de Johannes Weiss. A diferencia de lo que algunos pretenden, los fundamentos de la imagen del Jesús escatológico no han sido en absoluto minados. Su solidez se prueba no solo en el respaldo textual, sino también en el hecho de que los intentos por impugnarlos los dejan una y otra vez intactos.

Más aún, el paradigma del Jesús no escatológico (o no apocalíptico) no solo no es consistente, sino que debe omitir o interpretar de modo forzado y tendencioso -por no decir inverosímil- una gran cantidad de material evangélico. Además, no parece poder explicar de manera plausible el hecho crucial e indudable de que Jesús el galileo fue ejecutado con mors aggravata en cruz por las autoridades romanas de Judea como pretendiente mesiánico. No hay, pues, razón alguna para prestar oídos a las sirenas de esa imagen de Jesús, y sí muchas en contra.

De hecho, los análisis efectuados han mostrado que los intentos recientes de desescatologizar al predicador galileo, lejos de ser el resultado de una inesperada sofisticación intelectual o una invención posmoderna, son solo un jalón más en una trayectoria que tiene su comienzo ya en las propias Escrituras cristianas ${ }^{118}$ y que es visible, una y otra vez, en la historia de la exégesis neotestamentaria. El Jesús no apocalíptico no es más que la reedición norteamericana en las postrimerías del s. XX, con otros ropajes, de la teología liberal europea del s. XIX. Contemplada en su contexto diacrónico, no es sino la enésima manifestación, en la historia de la investigación, de un procedimiento exegético que, desde la apologética de Ritschl, se ha exhibido en numerosas variaciones a lo largo del s. XX (piénsese en C. H. Dodd, T. Francis Glasson, John A. T. Robinson o G. B. Caird, que sirven de estandartes a legiones de estudiosos).

Estas constataciones hacen temer que en (al menos algunos de) los alegatos contemporáneos a favor de un Jesús no apocalíptico pueda haber algo más, o algo menos, que una genuina y legítima aspiración al rigor histórico. Ciertamente, uno debe ser cauto en extremo a la hora de sugerir la presencia de subtextos o agendas ocultas en el ámbito académico ${ }^{119}$, pero en este caso todo apunta a que hay en juego factores extraepistémicos. El Jesús apocalíptico tiene varios rasgos que lo hacen difícilmente digerible: un sujeto que cometió importantes errores de cálculo ${ }^{120}$, que anunció el juicio (y la gehenna con su fuego inextinguible), cuya visión escatológica comporta

\footnotetext{
${ }^{118}$ La reinterpretación espiritualizante de una tradición escatológico-apocalíptica no la hallamos únicamente en textos «heterodoxos» como el Evangelio de Tomás, sino que aparece en los propios escritos neotestamentarios -2Pe 3, 3-4 y en especial el influyente Evangelio de Juan, que rechaza explícitamente interpretaciones de logia tradicionales que sin duda crearon preocupación en al menos algunos fieles $(2,19-22 ; 21,20-23 ;$ cf. 16, 1624), mediante una reinterpretación de la muerte y resurrección de Jesús.

119 Tanto más, cuanto que cabe detectar también la utilidad ideológica de un Jesús apocalíptico; cf. J. S. Kloppenborg, «As One Unknown, Without a Name? Co-opting the Apocalyptic Jesus», en Kloppenborg Marshall (eds.), Apocalypticism, Anti-Semitism and the Historical Jesus, pp. 1-23.

${ }^{120}$ Los humildes no han heredado la tierra, los pobres y los hambrientos no han sido saciados, los últimos no han pasado a ser los primeros. Es elocuente en este sentido algo de lo que Crossan responde a Allison: «Having said that Jesus and all other millenarian prophets were wrong (so far), you could hardly claim that God raised Jesus from the dead to prove he alone was transcendentally wrong» (en Miller, (ed.), The Apocalyptic Jesus, p. 55).
} 
el ejercicio de la violencia divina ${ }^{121}$, y cuya ética parece en buena parte determinada por su espera de una transformación inminente del mundo -recuérdese la noción de Interimsethik usada por Schweitzer-resulta sin duda incómodo y desconcertante para muchas mentalidades y sensibilidades ${ }^{122}$. Como ya advirtió el erudito alsaciano, este Jesús pertenece a un mundo que no es el nuestro, y resulta en él profundamente extraño e inutilizable ${ }^{123}$. El hecho de que tantos exegetas (y, en su estela, tantos teólogos) contemporáneos opten por un Jesús no apocalíptico - o cuyos rasgos apocalípticos se ven muy difuminados- a pesar de su extrema implausibilidad histórica, resulta mucho más comprensible a esta luz. La lógica subyacente parece ser: mejor aferrarse a un clavo ardiendo que desembocar en una aporía.

Así pues, en los supuestamente sofisticados argumentos a favor de un presunto Jesús no apocalíptico no parece haber, en último término, nada sino estrategias de inmunización excogitadas por la necesidad ideo(teo)lógica ${ }^{124}$. Es de temer, por tanto, que las reconstrucciones logradas de este modo estén conformando los hechos al lecho de Procrustes de esquemas y prejuicios dogmáticamente determinados, produciendo - una vez más- una visión mutilada y distorsionada del predicador galileo. Acostumbrado ya a detectar por doquier tales mistificadoras maniobras, el historiador de los orígenes cristianos vuelve a sumergirse en sus textos, preguntándose ya dónde se topará con la siguiente.

\footnotetext{
121 «God will not, perhaps cannot, rectify injustice through the violence and power of apocalypse» (Patterson, «The End of Apocalypse», p. 42, cursiva original).

122 Como lo reconocen los propios propugnadores del Jesús no apocalíptico: «New Testament theology must still face the uncomfortable fact that apocalyptic thinking shaped the way many early Christians came to see Jesus» (Patterson, «The End of Apocalypse», p. 41; en la p. 45, se refiere a «the offense of apocalyptic»).

123 «Jesus the apocalyptic Jew [...] remains for many New Testament scholars an awkward and unwelcomed stranger» (P. Fredriksen, «What you see is what you get: Context and Content in Current Research on the Historical Jesus», Theology Today 52 (1995), pp. 75-97, p. 76). Resulta instructivo que uno de los más competentes y honrados estudiosos contemporáneos de la figura histórica de Jesús, el protestante estadounidense Dale C. Allison, al evaluar el impacto del estudio histórico en su concepción teológica, apueste por una reinterpretación escatológica que se ve obligada a prescindir de Jesús y de los autores bíblicos: «An unbiased reading of the evidence informs us that the ancients in general and Jesus and particular took their eschatology much more literally than do many of us. So here we must go our own way, without Jesus in the lead, just as we must go our own modern way in reinterpreting Genesis - and any number of other biblical texts - in opposition to the assumptions of our predecessors in the faith, including the biblical writers» (The Historical Christ, p. 99).

${ }^{124}$ Hiers (The Historical Jesus, p. 116) llega a sugerir que afirmar que el Jesús del Cuarto Evangelio (en gran parte no escatológico) y el Jesús histórico son el mismo sería hoy «an act of bad faith». Por su parte, C. Sullivan (Rethinking Realized Eschatology, Macon, 1988, p. 115) afirma que la escatología realizada «is a scholarly means for engaging in intellectual dishonesty». Resulta arriesgado formular juicios morales cuando se desconocen las intenciones, pero estos graves asertos expresan claramente lo que puede inspirar la observación del décalage entre las pretensiones modernas del Jesús no apocalíptico y su llamativa fragilidad argumentativa.
} 